Special issue in honor of Prof. H.K. Lichtenthaler

REVIEW

\title{
Can chlorophyll fluorescence imaging make the invisible visible?
}

\author{
R. VALCKE
}

Molecular and Physical Plant Physiology, Faculty of Sciences, Hasselt University, B-3590 Diepenbeek, Belgium

\begin{abstract}
Chlorophyll fluorescence has developed into a well-established noninvasive technique to study photosynthesis and by extension, the physiology of plants and algae. The versatility of the fluorescence analysis has been improved significantly due to advancements in the technology of light sources, detectors, and data handling. This allowed the development of an instrumention that is effective, easy to handle, and affordable. Several of these techniques rely on point measurements. However, the response of plants to environmental stresses is heterogeneous, both spatially and temporally. Beside the nonimaging systems, low- and high-resolution imaging systems have been developed and are in use as real-time, multi-channel fluorometers to investigate heterogeneous patterns of photosynthetic performance of leaves and algae. This review will revise in several paragraphs the current status of chlorophyll fluorescence imaging, in exploring photosynthetic features to evaluate the physiological response of plant organisms in different domains. In the conclusion paragraph, an attempt will be made to answer the question posed in the title.
\end{abstract}

Keywords: chlorophyll fluorescence imaging; hyperspectral imaging; image processing; multicolour fluorescence imaging; stresses; thermal imaging.

\section{Introduction}

In natural conditions, plants (algae, Bryophytes, Pteridophytes, gymnosperms, angiosperms) will be subjected sooner or later to stress. Growth and development of plants depend on and are regulated by mechanisms that absorb light and convert this in usable chemical energy: photosynthesis. Interactions with abiotic and biotic factors of the environment result in alterations in the metabolism of sugars, sink/source relationships, and in physiology in general. To understand these mechanisms, plants are studied under controlled conditions (growth chambers, greenhouses) or in the field. A whole bunch of techniques are available: from 'omics' (genomics, epigenomics, transcriptomics, proteomics, metabolomics, microbiomics) to nondestructive methods, such as gasexchange and optic-based techniques. The presence of an endogenous molecule, chlorophyll ( $\mathrm{Chl}$ ), as part of the photosynthetic machinery, which not only absorb but also re-emit light energy, enables to mine the physiological state of plant organisms. The emitted light, which is called fluorescence, can be monitored with nonimaging and imaging techniques. The signals, which change during illumination and which are affected by environmental conditions, deliver information on how plant organisms cope with stresses.

\section{Highlights}

- Chlorophyll fluorescence imaging and other imaging methods

- Domains in which chlorophyll fluorescence imaging is used

- Data processing
Received 7 January 2021

Accepted 9 March 2021

Published online 4 May 2021

e-mail: roland.valcke@uhasselt.be

Abbreviations: Chl-F - chlorophyll fluorescence; Chl-FI - chlorophyll fluorescence imaging; DCMU - 3-(3,4-dichlorophenyl)1,1-dimethylurea; DLE - delayed light emission; $\mathrm{F}_{0}$ - minimal fluorescence; FLI - fluorescence lifetime imaging; $\mathrm{F}_{\mathrm{v}}$ - variable fluorescence; $\mathrm{F}_{\mathrm{V}} / \mathrm{F}_{\mathrm{M}}$ - maximal quantum yield of PSII photochemistry; LED - light-emitting diode; LIF - laser-induced fluorescence; NIR - near infrared; RGB - red-green-blue; SIF - sun-induced fluorescence; SWIR - short wave infrared; VIS - visible.

Conflict of interest: The author declares no conflict of interest. 
Chlorophyll fluorescence (Chl-F) is widely used in basic and applied research in studies on abiotic and biotic stress, metabolism, agriculture, ecology. The main advantage of this approach is its nondestructive/noninvasive character. Chl-F is considered as passive if the light source is sun and is termed the sun-induced fluorescence; it is active when the excitation source is a lamp or a laser. Furthermore, Chl-F is prompt or delayed. Prompt Chl-F is the red fluorescence emitted within nanoseconds after the onset of the illumination of the sample, delayed Chl-F is recorded in the dark after illumination.

For the reader interested in the history of the light emission in general and of Chl-F by plant material, more detailed information can be found in the reviews of Govindjee (1995), Kalaji et al. (2012), and Harvey (1957) while the role of Kautsky's contributions and their influence on the further Chl-F research is highlighted by Lichtenthaler (1992).

Since the pioneering work of Kautsky and his coworkers in 1931 (Kautsky and Hirsch 1931), the instrumentation and methodology to measure Chl-F has evolved tremendously. For a more detailed description of a history and progress of fluorometers till 2012, I refer to the papers of Kalaji et al. (2012) and Fernandez-Jaramillo et al. (2012). A more recent survey can be found in Walker et al. (2018). Although no real standard algorithms for Chl-FI are available, examples of protocols for some typical measurements are provided by Lawson and VialetChabrand (2018).

The nonimaging Chl-F approaches enable to study the fast fluorescence induction kinetics. These are in essence point measuring methods. To obtain a good image of the physiological heterogeneity of for instance a leaf, a great number of measurements is needed. The power of imaging approaches is the ability to study the processes of the whole cells, leaves, and even plants and canopies and image the hidden information behind the heterogeneity of the samples. In this review, a selection of papers, which cover a few domains, in which chlorophyll fluorescence imaging is widely used, is reported. The nonimaging Chl fluorescence methods, techniques, and applications will not be discussed. There are many excellent reviews available. A selection of commercial nonimaging and imaging Chl fluorometers is given in a supplementary file 1S (supplement).

Following a discussion on Chl-FI and kinetic fluorescence imaging, short reviews on several topics will be handled. These topics are: abiotic - biotic stress, herbicides, lower plants (algae - lichens - mosses), plant phenotyping, spatiotemporal variations - metabolic perturbation - leaf heterogeneity, agriculture, ecosystems, sun-induced fluorescence, combinations of Chl-FI with hyperspectral - multispectral - thermal imaging, and image processing - statistical analysis. These recapitulations are a selection and consequently, not complete.

\section{Chl fluorescence imaging}

The first imaging system was a thermal imager based on thermistors. It was built in 1950 by Bowling Barnes in the
USA, a student of Marianus Czerny, who was professor of physics at Goethe Institute Frankfurt University, Germany (Ammer and Ring 2019). The beginning of imaging spectrometry is rooted in the launch of Landsat-1 (ETRS-1) in 1972 (Goetz 2009). The first recorded Chl-F images using instruments were taken by Sundbom and Björn (1977). They measured the delayed fluorescence (delayed light emission, DLE) at a near distance of a few centimeters to the leaf. This technique, image-intensified photography, was then used by Ellenson and Amundson (1982) to detect early plant stress. Later on, Omasa et al. (1987) took images of the prompt fluorescence by illuminating leaves with continuous blue light (again at a distance) to follow the photosynthetic induction kinetics (Kautsky effect). Using short blue light pulses at high repetition rates as an excitation source to illuminate samples, the kinetics of photochemical and nonphotochemical quenching was determined and presented as images (Daley et al. 1989, Osmond et al. 1990, Siebke and Weis 1995, Bro et al. 1996). This technique is known as Pulse Amplitude Modulation, or PAM. From the 1990s on, improved camera and frame grabber performance, coupled with developments in computer hard- and software, enable the technique of Chl-FI to evolve into a ubiquitous tool for determining the molecular and physiological mechanisms of photosynthesis. Chl-FI alone or combined with hyperspectral and/or thermal imaging became very promising to study fundamental mechanisms, which regulate photosynthesis and with extension also other physiological processes. For an introduction to Chl-FI and its state till 2004, see the papers of Nedbal and Whitmarsh (2004) and Oxborough (2004).

One of the major challenges in Chl-FI is to image the fluorescence kinetics. Kinetic fluorescence imaging, dynamic chlorophyll fluorescence imaging and/or fluorescence lifetime measurements in photosynthesis research, have been applied already in early 1970 s by Briantais et al. (1972) in Chlorella pyrenoidosa, and in 1980 by Malkin et al. (1980) in plant leaves. Several reviews describing the methodology and the application of these methods in photosynthesis research before 2000 can be consulted (Gilmore and Govindjee 1999, Morales et al. 1999, Agati et al. 2000). Compared to fluorescence intensity, fluorescence lifetime measurement of $\mathrm{Chl}$ is more sensitive as it is mostly independent of the pigment concentration (Lakowicz 2006) but is directly affected by the molecular environment. The Chl fluorescence induction transients occur in milliseconds to many second range and depend on the photosynthetic sample. Fluorescence lifetime imaging (LFI) provides valuable, additional information on the different quenching mechanisms involved in the de-excitation of Chl $a^{*}$. Holub et al. (2000) described an instrument that allows the measurements of LFI of leaves, subcellular structures of intact plants, and single cells of algae. They used the same approach in a study on the fluorescence characteristics of two nonphotochemical quenching ( $n p q)$ mutants of Chlamydomonas reinhardtii and the effect of several photosynthetic inhibitors (Holub et al. 2007). Nedbal et al. (2000) also described 
an instrument; this one combined the advantage of high frequency modulated light with two-dimensional imaging of Chl fluorescence. This fluorometer provided accurate mapping of $\mathrm{F}_{0}$ and $\mathrm{F}_{\mathrm{V}}$ and nonphotochemical quenching and could be used to record fluorescence images of leaves in daylight under field conditions. A custom build Chl-FI system (FIS-system, developed at Hasselt University, former Limburgs Universitair Centrum) (Fig. 1) was used in studies on the effect of heavy metals on bean leaves (Ciscato and Valcke 1998), for quality assessment of fruit (Ciscato 2000), and to image treatment of apple fruit with ethylene (Huybrechts 2003) (see paragraph 'Agriculture'). The FIS-system has been further exploited to image the nonphotochemical quenching of a viral infection of tobacco plants (Pérez-Bueno et al. 2006). In this work, the whole quenching analysis was carried out by Chl-FI from the early to the later stages of infection of the host plant. A portable system developed by the same UHasselt group (Fig. 2) was used to analyse the effect of ozone on rape and beech (Gielen et al. 2006, 2007a), climate change on grasslands species (Gielen et al. 2005, 2007b), and for the prediction of bitter bit in apple (Lötze et al. 2006) (see also paragraph 'Image processing - statistical analysis').

A photon-excitation Chl fluorescence lifetime imaging combined with flow cytometry was used to study the effect of two mercury compounds [inorganic mercury $\left(\mathrm{Hg}^{\mathrm{II}}\right)$ and methylmercury $\left.(\mathrm{MeHg})\right]$ on Thalassiosira weissflogii, a marine diatom (Wu et al. 2012) and of an in vivo assessment of cadmium toxicity in the same marine diatom (Zeng et al. 2012). A new set of parameters to estimate and image nonphotochemical quenching in PSII associated antenna complexes was derived by Tietz et al. (2017). Their approach allowed high-throughput and field applications.
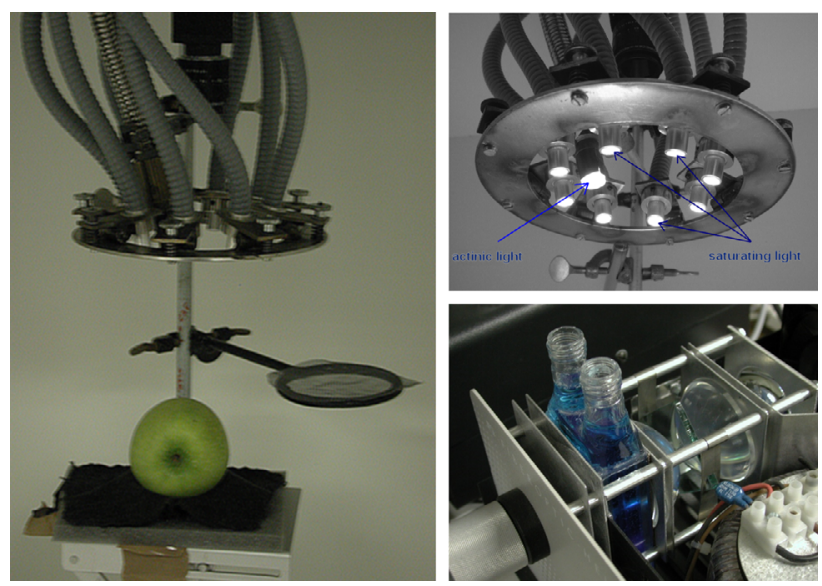

Fig. 1. Fluorescence Imaging System (FIS) (UHasselt). Left panel: light guiding optical fibres, camera in between, apple sample cv. Jonagold. Upper right panel: detail of illumination system indicating fibres for actinic and saturating light. Lower right panel: lamp system: $150-\mathrm{W}$ halogen lamp, saturated $\mathrm{CuSO}_{4}$ solution as blue filter (Ciscato 2000). This system was used for the quenching analysis in paper of Pérez-Bueno et al. (2006).
Other studies, in which dynamic Chl-FI was used, include the analysis of chlorosis induced by plant virus infection (Lei et al. 2017), PSII-inhibiting herbicide (Noble et al. 2017), reversible UV-induced photosynthetic activity (Kristoffersen et al. 2016), discrimination of maize genotypes to drought (de Sousa et al. 2017), dynamic photosynthetic fingerprints of salt overly sensitive (sos)mutants of Arabidopsis to drought stress (Sun et al. 2019), and sensitivity to $\mathrm{pH}$ of Chlorella algae (Marcek Chorvatova et al. 2020). A combination of kinetic Chl fluorescence and multicolour fluorescence imaging was used in a study on drought stress in Arabidopsis (Yao et al. 2018). A comprehensive review on multicolour fluorescence imaging is given by Lichtenthaler (2021) in this Special Issue.

The imaging of the fast fluorescence induction, the OJIP-kinetics has been major challenge due to the limitation of the speed of the recording cameras. Küpper et al. (2019) developed a new macroscopic and microscopic system equipped with an ultrafast camera. The heterogeneity of different fluorescence parameters across the surface of the leaf and between the veins and photosynthetic tissues has been imaged. The authors applied this new approach on a study on zinc and cadmium toxicity.

\section{Abiotic stress}

Plant species have at their disposal acclimation mechanisms to cope with abiotic and biotic stress in changing natural environments. Abiotic stresses, such as toxicity of heavy metals, deficiencies in mineral nutrients, exposure to extreme temperatures, drought, high light, air pollution, senescence, and phytotoxins (including herbicides)

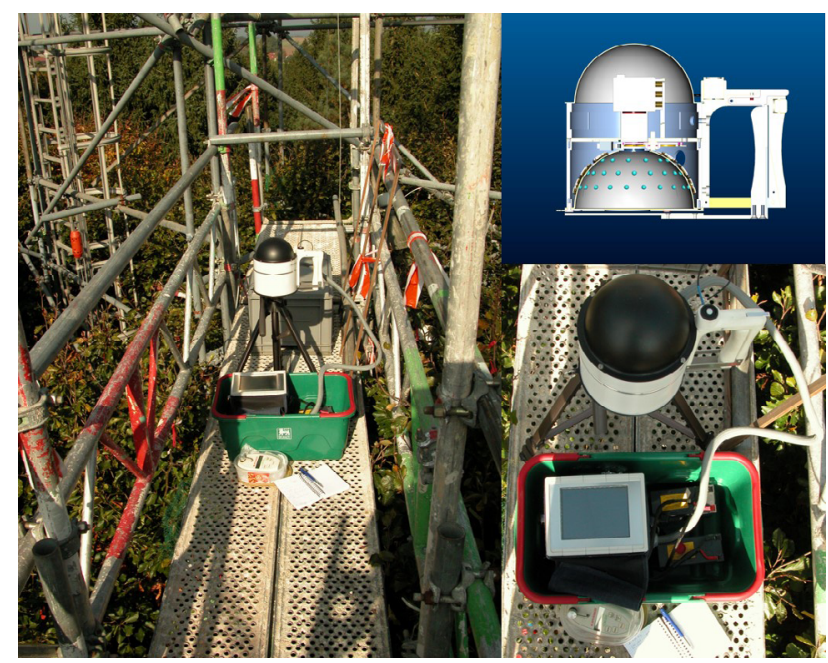

Fig. 2. Custom-build portable FIS-prototype consisting of a measuring unit mounted on a tripod and the control unit (PC). Left panel: equipment at the field site 'Kranzberger Forst' (Freising, Germany) at 24-m height (Gielen et al. 2007a). Right panels: upper cross-section measuring unit. Prototype was developed in cooperation with 'Maastricht Instruments', Maastricht, The Netherlands (European patent EP-BI-2 060 905). 
has been extensively studied by Chl-FI. In contrast to the nonimaging Chl-F, Chl-FI enables to image the heterogeneous sensitivity of PSII reactions throughout a leaf. In Tables 1 and 2, a selection of Chl-FI studies, which highlight the impact of several abiotic stresses on the photosynthetic performance, is presented.

Combination of gas-exchange analysis and Chl fluorescence imaging has been performed by Massacci et al.

Table 1. The list of selected works describing Chl-FI to study plant responses to abiotic stress.

\begin{tabular}{|c|c|c|}
\hline Type of abiotic stress & Plant species & Reference \\
\hline Cadmium toxicity & $\begin{array}{l}\text { Noccaea caerulescens (L.) } \\
\text { Sedum plumbizincicola } \\
\text { Phaseolus vulgaris L. } \\
\text { Thalassiosira weissflogii (CCMP 1587) } \\
\text { Zea mays L. } \\
\text { Noccaea caerulescens (L.) } \\
\text { Noccaea ochroleucum (L.) } \\
\text { Glycine max (L.) } \\
\text { Arabidopsis thaliana }\end{array}$ & $\begin{array}{l}\text { Bayçu et al. }(2018) \\
\text { Zhao et al. }(2019) \\
\text { Ciscato and Valcke (1998) } \\
\text { Zeng et al. }(2012) \\
\text { Zhao et al. }(2018) \\
\text { Küpper et al. }(2019)\end{array}$ \\
\hline Zinc deficiency & $\begin{array}{l}\text { Noccaea caerulescens (L.) } \\
\text { Noccaea ochroleucum (L.) } \\
\text { Glycine max Merr. } \\
\text { Arabidopsis thaliana L. }\end{array}$ & Küpper et al. (2019) \\
\hline Mercury toxicity & Thalassiosira weissflogii & Wu et al. (2012) \\
\hline High light & Arabidopsis thaliana $\mathrm{L}$. & Bielczynski et al. (2017) \\
\hline Water/drought & $\begin{array}{l}\text { Rosa } \times \text { hybrida }(\mathrm{L} .) \\
\text { Quercus ilex } \mathrm{L} . \\
\text { Ramonda serbica } \\
\text { Ramonda nathaliae } \\
\text { Arabidopsis thaliana } \mathrm{L} . \\
\text { Arabidopsis thaliana } \mathrm{L} . \\
\text { Cephalolichens: Lobaria species } \\
\text { Zea mays L. } \\
\text { Brassica napus } \mathrm{L} . \\
\text { Arabidopsis thaliana } \mathrm{L} . \\
\text { Arabidopsis thaliana } \mathrm{L} . \\
\text { Cucumis sativus } \mathrm{L} .\end{array}$ & $\begin{array}{l}\text { Calatayud et al. (2006) } \\
\text { Guárdia et al. (2012) } \\
\text { Gashi et al. }(2013) \\
\text { Bresson et al. }(2015) \\
\text { Mishra et al. }(2016) \\
\text { Gauslaa et al. }(2017) \\
\\
\text { de Sousa et al. }(2017) \\
\text { Guadagno et al. }(2017) \\
\text { Yao et al. }(2018) \\
\text { Sun et al. }(2019) \\
\text { Zhuang et al. }(2020)\end{array}$ \\
\hline Ozon damage & $\begin{array}{l}\text { Phaseolus vulgaris L. } \\
\text { Brassica napus L. } \\
\text { Fagus sylvatica L. } \\
\text { Helianthus annuus L. } \\
\text { Glycine max Merr. }\end{array}$ & $\begin{array}{l}\text { Leipner et al. (2001) } \\
\text { Gielen et al. (2006) } \\
\text { Gielen et al. (2007a) } \\
\text { Endo and Omasa (2007) } \\
\text { Chen et al. (2009) }\end{array}$ \\
\hline Freezing damage - cold acclimation & $\begin{array}{l}\text { Arabidopsis thaliana } \mathrm{L} . \\
\text { Senecio incanus } \mathrm{L} . \\
\text { Rhododendron ferrugineum } \mathrm{L} . \\
\text { Poa alpina } \mathrm{L} . \\
\text { Cinnamomum camphora } \mathrm{L} . \\
\text { Arabidopsis thaliana } \mathrm{L} . \\
\text { Cichorium intybus } \mathrm{L} . \\
\text { Cichorium intybus } \mathrm{L} . \\
\text { Arabidopsis thaliana } \mathrm{L} .\end{array}$ & $\begin{array}{l}\text { Ehlert and Hincha (2008) } \\
\text { Devacht et al. }(2011) \\
\text { Lootens et al. }(2011) \\
\text { Mishra et al. (2014) }\end{array}$ \\
\hline Chilling injury & $\begin{array}{l}\text { Calathea makoyana } \\
\text { Solanum lycopersicum L. } \\
\text { Cucumis sativus L. }\end{array}$ & $\begin{array}{l}\text { Hogewoning and Harbinson (2007) } \\
\text { Dong et al. }(2019,2020) \\
\text { Lu and Lu }(2020)\end{array}$ \\
\hline Heat stress & Hordeum spontaneum Koch & Jedmowski and Brüggemann (2015) \\
\hline Climate change & $\begin{array}{l}\text { Rumex acetosa } \mathrm{L} \text {. } \\
\text { Plantago lanceolata } \mathrm{L} \text {. } \\
\text { Grassland communities }\end{array}$ & $\begin{array}{l}\text { Gielen et al. (2005) } \\
\text { Gielen et al. (2007b) }\end{array}$ \\
\hline Leaf senescence & $\begin{array}{l}\text { Arabidopsis thaliana } \mathrm{L} \text {. } \\
\text { Arabidopsis thaliana } \mathrm{L} \text {. }\end{array}$ & $\begin{array}{l}\text { Wingler et al. (2004) } \\
\text { Lyu et al. (2019) }\end{array}$ \\
\hline
\end{tabular}


Table 2. The list of selected works describing Chl-FI and UV-laser-induced fluorescence imaging to study plant responses to herbicides/ phytotoxins.

\begin{tabular}{|c|c|c|}
\hline Type of herbicide & Plant species & Reference \\
\hline DCMU & Nicotiana tabacum $\mathrm{L}$. & Lichtenthaler et al. (1997) \\
\hline Imazapyr & Arabidopsis thaliana $\mathrm{L}$. & Barbagallo et al. (2003) \\
\hline Phenylurea herbicides & Phaseolus vulgaris L. & Chaerle et al. (2003) \\
\hline DCMU & Spirogyra distenta & Endo and Omasa (2004) \\
\hline DCMU & $\begin{array}{l}\text { Phaeodactylum tricornutum } \\
\text { Chlorella vulgaris } \\
\text { Desmodesmus subspicatus }\end{array}$ & Schreiber et al. (2007) \\
\hline DCMU - atrazine - hexazinone - simazine & $\begin{array}{l}\text { Phaeodactylum tricornutum } \\
\text { Chlorella vulgaris }\end{array}$ & Muller et al. (2008) \\
\hline DCMU & $\begin{array}{l}\text { Phaseolus vulgaris L. } \\
\text { Digitalis purpurea L. }\end{array}$ & Lichtenthaler et al. (2013) \\
\hline $\begin{array}{l}\text { Fenoxaprop-P-ethyl } \\
\text { Mesosulfuron-methyl } \\
\text { Iodosulfuron-methyl-sodium }\end{array}$ & Alopecurus myosuroides Huds. & Kaiser et al. (2013) \\
\hline Methyl viologen & Oryza sativa $\mathrm{L}$. & Kasajima (2017) \\
\hline DCMU - Irgarol 1051 & $\begin{array}{l}\text { Chlorella sp. } \\
\text { Chlamydomonas sp. }\end{array}$ & Kottuparambil et al. (2017) \\
\hline $\begin{array}{l}\text { Desmediphan - phenmedipham - ethofumasate - } \\
\text { lenacil - metribuzin - flufenacet }\end{array}$ & $\begin{array}{l}\text { Beta vulgaris subsp. vulgaris } \\
\text { Glycine max L. }\end{array}$ & Weber et al. (2017) \\
\hline $\begin{array}{l}\text { Metribuzin - clomazone - dimethenamid - flufenacet - } \\
\text { thifensulfuron - bentason - fluaziflop-P-butyl }\end{array}$ & Glycine $\max \mathrm{L}$. & Li et al. (2018) \\
\hline Chlorosulfuron & Zea mays L. & Zhao et al. (2018) \\
\hline DCMU - glyphosate - chromium & Arabidopsis thaliana $\mathrm{L}$. & Segečová et al. (2019) \\
\hline DCMU & Sorghum bicolor L. & Herritt et al. (2020) \\
\hline
\end{tabular}

(2008) on drought stress and by Duan et al. (2019) on sulphur dioxide exposure. The water usage and the effect of $\mathrm{SO}_{2}$ exposure on photosynthetic activity of street trees has been visualized with seemingly a strange combination of cold neutron and Chl-FI by Matsushima et al. (2009) and spatial heterogeneity of cadmium effects on Salvia sclarea leaves was revealed by Chl-FI combined with laser ablation inductively coupled plasma mass spectrometry (Moustakas et al. 2019).

An important application of Chl-FI concerns the studies on the effect of herbicides on the photosynthetic apparatus and the physiology of plants in general. A wellstudied herbicide is DCMU [3-(3,4-dichlorophenyl)1,1-dimethylurea], also known as diuron, which inhibits the electron transport and quantum conversion by binding to PSII. The application of herbicides in agriculture is widespread. In precision agriculture, sensor technologies became expedient tools. Besides Chl-FI as described in this review, noninvasive UV-laser-induced fluorescence imaging systems has proven useful as a diagnostic tool for plant stress in general (Lichtenthaler et al. 1996, Lichtenthaler and Miehé 1997, Buschmann and Lichtenthaler 1998) and to investigate the uptake and distribution of herbicides and phytotoxins in each point of the leaf surface. A recent review by Sánchez-Moreiras et al. (2020) discussed Chl-FI for discriminating plant responses to phytotoxic stresses. A further selection of publications in this domain is presented in Table 2.

\section{Biotic stress}

Photosynthesis and its regulation is a pivotal process in defense mechanisms against biotic stress in plants. Since the introduction of Chl-FI as a diagnostic tool, lot of progress has been made. An excellent recent review on plant responses to biotic stress by $\mathrm{Chl}$ fluorescence imaging is from the hand of Pérez-Bueno et al. (2019). A further selection of papers on this topic, which are not mentioned in the review of Pérez-Bueno, are presented in Table 3. Furthermore, some of these papers are also cited in other paragraphs of this review.

\section{Algae - lichens - mosses}

As described in previous paragraphs, Chl-FI is a powerful tool to study the physiology of leaves and whole terrestrial higher plants but it has also broad use in the study of photosynthetic characteristics of lichens, mosses, marine and freshwater organisms (algae), and photosynthetic bacteria. In a genetic approach, Niyogi et al. (1997) used video imaging to analyse the $\mathrm{Chl}$ fluorescence quenching of Chlorella xanthophyll cycle mutants. A major component of Antarctic vegetation are the lichens. They are subjected to a variety of environmental stresses of which drought and high light intensities are the most important ones. The global warming of the atmosphere leads also in Antarctic and Arctic regions to an increase in air temperature which 
Table 3. List of selected works describing Chl-FI to study plant responses to biotic stress.

\begin{tabular}{|c|c|c|}
\hline Plant pathogen & Plant species & Reference \\
\hline Phytophthora nicotianae & Nicotiana tabacum $\mathrm{L}$. & Scharte et al. (2005) \\
\hline Phytophthora alni subsp. alni & Alnus glutinosa $\mathrm{L}$. & Pfanz et al. (2015) \\
\hline Plasmopara viticola & Vitis vinifera (Chardonnay) & Cséfalvay et al. (2009) \\
\hline Candidatus Liberibacter spp. & Citrus spp. & Cen et al. (2017) \\
\hline Corynespora cassiicola & Glycine $\max \mathrm{L}$. & Fortunato et al. (2018) \\
\hline Venturia inaequalis (Cooke) & Malus $\times$ domestica $\mathrm{cv}$. Braeburn & Delalieux et al. (2009) \\
\hline Venturia inaequalis (Cooke) & Grafted apple trees (not specified) & Belin et al. (2013) \\
\hline Heterobasidion parviporum & Picea abies L. & Wen et al. (2019) \\
\hline Xanthomonas cannabis & Nicotiana benthamiana & Méline et al. (2020) \\
\hline
\end{tabular}

has serious consequences for fauna and flora. Barták et al. (2004) studied the effect of high-light stress and the photoprotective mechanisms in Umbilicaria antarctica. Using Chl-FI, the spatial distribution of several Chl fluorescence parameters was analysed. The results indicated that lichens do show a strong recovery indicating a sufficient capacity of photoprotective mechanisms to cope with low-temperature photoinhibition. A microscopic multicolour variable $\mathrm{Chl}$ fluorescence imaging approach was exploited for rapid assessment of different oxygenic phototrophs and single cell photosynthesis (Trampe et al. 2011). To discriminate and quantify the distribution of benthic cyanobacteria and diatoms, an autofluorescence imaging system was developed and applied by Carreira et al. (2015). Chl-FI delivers essential information on the PSII photochemical efficiency of microphytobenthic cells (Oxborough et al. 2000), of Antarctic bottom-ice algae to light and salinity during melting (Ryan et al.2011), on the photobiology of sea ice algae during initial spring growth in Kangerlussaq, West Greenland (Hawes et al. 2012), and on the response of Antarctic sea-ice algae on $\mathrm{pH}$ (Castrisios et al. 2018). An extensive study on resurrection of chlorolichens in humid air and its role in the activation of photosynthetic activity measured by monitoring PSII activation by Chl-FI was performed by Phinney et al. (2018, 2019). An interesting study on corals has been published by Wangpraseurt et al. (2019). They studied the optical properties of corals using Chl-FI (I-PAM) and the impact upon photosynthetic parameters. The authors indicate that the results have important implications for the use of variable Chl fluorescence in ecophysiological studies not only of coral stress and photosynthesis, but also for plants and biofilms. In a perspective paper, Chen et al. (2019) investigated the possibility to use mosses as indicators for several stresses in general and for heavy metal pollution in water in particular.

\section{Plant phenotyping}

The unravelling and understanding of crop genomes has made tremendous progress thanks to continually expanding genomic technologies. However, due to a lack of highquality phenotypic data, the impact of genomic data on crop improvement remains unsatisfactory. Photosynthetic productivity and robustness depend on complex sets of traits and on many interacting factors. This so called 'environmental phenometrics' (Munns et al. 2010) requires noninvasive probes of relevant phenotypes that can be applied to many plants. During the past decades, several platforms consisting of mechanized transport systems and several sensors for phenotyping have been developed, i.e., TraitMill (CropDesign, UK), PlantScreen (Photon System Instruments, CZ), Scanalyzer (Lemnatec, Germany). To overcome critical limitations of the above techniques, Cruz et al. (2016) developed the 'Dynamic Environmental Photosynthesis Imager' (DEPI). This enables direct assessment of rapid and long-term responses to dynamic environmental conditions of large number of plants in parallel. Consult this paper for a detailed description of the system and the previous mentioned platforms. High-throughput screening methods using spectroscopic techniques, such as RGB, LEDbased multi-actinic illumination systems, and Chl fluorescence, have been used to study crop physiology and improvement (Harbinson et al. 2012, Wang et al. 2018), traits that contribute to salt salinity (Awlia et al. 2016), photosynthetic light responses (Serôdio et al. 2018), stage of development (Simko et al. 2016), drought stress (Yao et al. 2018), plant-pathogen interactions (Hupp et al. 2019, Wang et al. 2019), resistance to pathogens (Rousseau et al. 2013), photoprotection in leaves under controlled gaseous conditions (McAusland et al. 2019), and genetic variation and loci for photosynthetic trait (Prinzenberg et al. 2018). A multicolour fluorescence imaging approach has been used by Pérez-Bueno et al. (2016) to explore the method to detect diseases in plant phenotyping.

Recently, papers on methodology and excellent reviews on phenotyping and high-throughput screening have been published. An establishment of integrated protocols for automated plant phenotyping was described by Tschiersch et al. (2017). Humplík et al. (2015) discussed automated phenotyping of plant shoot systems which use imaging methods (RGB, Chl fluorescence, thermal, and hyperspectral) to analyse plant stress responses. For the exploration of large Chl-FI datasets, an automated procedure has been developed by Rousseau et al. (2015a). A review on genetic Chl fluorescence-based screens of libraries of Arabidopsis and Chlamydomonas can be found 
in Rühle et al. (2018). The review paper of Mir et al. (2019) gives the current status on sophisticated noninvasive imaging including Chl-FI, spectroscopy, image analysis, robotics, high-performance computing facilities, and phenomics databases.

Despite the recent developments in plant phenomic approaches and facilities, there still exist major bottlenecks in the phenotypic and genotypic evaluation of photosynthesis-related traits. An excellent discussion on this topic was published in a review by van Bezouw et al. (2019).

\section{Spatio-temporal variations - metabolic perturbation - leaf heterogeneity}

'Since fluorescence from photosynthetic systems is inversely related to the probability of photochemical trapping, the fluorescence induction caused by a dark-light transition provides useful information on the overall rate of flow of electrons through the electron transport chain'. This was written by Papageorgiou in 1975 (Papageorgiou 1975). Till then, to provide information about the physiological state of plants, most experimental systems used a single element detector. This means that only sampling an average from a region of interest was possible. Using video images of Chl-F, Daley et al. (1989) studied the topography of photosynthetic activity of leaves. They combined gas-exchange measurements with recording images of Chl-F during pulses of intense light following the method of Schreiber et al. (1986). The coefficients of nonphotochemical quenching were calculated pixel by pixel for each image. Using this approach, they were able to draw the topography of photosynthetic electron transport in a leaf and due to the combined gas exchange, also the distribution of stomatal conductance. The carbon assimilation in developing leaves of cucumber was studied by Croxdale and Omasa (1990a) using dynamic imaging of fluorescence kinetics. They showed that the spatial acquisition of photochemical activity was oriented in a basipetal direction as development of airspaces and stomata and the cessation of imported carbon. Fenton and Crofts (1990) studied the fluorescence induction in green plants and photosynthetic bacteria. Using computeraided fluorescence imaging, they followed the rapid induction curves exhibited by photosynthetic bacteria and fluorescence induction in pea leaves of which the stem was soaked in DCMU. They applied LUT colour scales to visualize more clearly different fluorescence parameters $\left[\mathrm{F}_{(\mathrm{i})}\right.$ at $20 \mathrm{~ms}, \mathrm{~F}_{(\mathrm{t})}$ at $3 \mathrm{~s}$, the variable fluorescence $F_{v}=F_{(t)}-F_{(i)}$, and the normalized fluorescence $\left.\mathrm{NF}=100 \times \mathrm{F}_{\mathrm{v}} / \mathrm{F}_{(\mathrm{i})}\right]$

During the late 1980s and in the following decade, the analysis of photosynthetic fluxes and control fluxes by metabolic processes in leaves was further explored, first with nonimaging techniques (Weis and Berry 1987, Genty et al. 1989), followed by imaging approaches (Croxdale and Omasa 1990b, Genty and Meyer 1995, Rolfe and Scholes 1995, Siebke and Weis 1995). Meng et al. (2001) visualized a sink-source transition in tobacco leaves using
Chl-FI. A comparison of Chl-FI with autoradiography of ${ }^{14} \mathrm{C}$-labelleld import showed that the tip of a young leaf is not a sink but acts as a source. The assimilation and induction images were complementary, a fast induction coincided with low assimilation zones and vice versa (Meng et al. 2001).

Spatio-temporal variations and metabolic regulation have been studied during day-night cycles and during endogenous rhythm in continuous light in the CAMplant Kalanchoë daigremontiana (Rascher and Lüttge 2002), during leaf senescence in Arabidopsis (Wingler et al. 2004), and in Rosa $\times$ hybrida leaves under water stress (Calatayud et al. 2006). A recent study using highthroughput delayed fluorescence imaging by Rees et al. (2019) in Triticum aestivum and Brassica napus, revealed that the age of the plant, light regime, and temperature significantly affect delayed fluorescence rhythms, reflecting underlying metabolic differences in the control of circadian rhythms.

The distribution of photosynthetic pigment content and photosynthetic activity among differentially pigmented sectors in variegated leaves of five cultivars of Coleus $\times$ hybridus, was estimated by image analysis and point data measurements of $\mathrm{Chl}$ fluorescence (Borek et al. 2016). The results showed that both analyses revealed a heterogeneity in leaf $\mathrm{Chl}$ fluorescence parameters within a leaf. This allowed for distinguishing mechanisms of excitation energy capture, transfer, and dissipation in differently pigmented sectors. The importance of the spatial distribution of $\mathrm{Chl}$ in leaves and the relation between leaf structure and carbon assimilation was studied using epi-fluorescence microscopy (Borsuk and Brodersen 2019). Based on their findings, the authors developed model equations for ecological and commercial species and plant functional types. This can be considered as an advancement toward more accurate photosynthesis modelling and understanding of intra-leaf physiology.

During the last decade, Chl fluorescence imaging techniques were further used in a study of the role of a biologically active compound of the brassinosteroids (24-epibrassinolide) in the regulation of photosynthetic characteristics and nitrogen metabolism of tomato seedlings under different stress conditions (Shu et al. 2016), on the effect of vascular connection in grafting union in Solanaceae species (Penella et al. 2017), and on the overexpression of the Rieske FeS protein on the electron transport rate and biomass yield in transgenic Arabidopsis thaliana (Simkin et al. 2017).

Plant growth is characterized by a continuous acclimation to dynamical changes in environmental conditions, such as irradiance, temperature, and humidity. This acclimation involves changes in how leaves grow and change their orientation, meaning changing their lightabsorption characteristics as well as the emission of Chl fluorescence in time. These dynamic properties can be monitored by 3-D imaging systems through algorithms that associate a particular 2-D shape to a known parameter. In their study, Bellasio et al. (2012) performed a computer reconstruction of plant growth and $\mathrm{Chl}$ fluorescence 
emission in three spatial dimensions. They used a goniometric system which included a reflectance and a fluorescence camera. The method described is very potent in capturing plant dynamics under no and mild stress, but fails under severe stress (e.g., wilted plants).

\section{Agriculture}

The quality and storage capability of fruits, vegetables, and seeds depend strongly on the environmental stresses when the trees, plants, and crops are exposed to during the growing season.

Assessment of grape fruit maturity plays an important role in the control for high-quality wine. Monitoring the phenolic contents of grape berries is strongly influenced by large spatial and temporal heterogeneity among different vineyards (Bramley 2005). Nondestructive optical methods to assess berry skin anthocyanins, based on sequential acquisition of $\mathrm{Chl}$ fluorescence under two excitations lights (green and red), have been developed. The logarithm of the red-excited to the green-excited Chl fluorescence $(\log$ FER) was found to be related to the absorbance of anthocyanins (Agati et al. 2007). Based on this knowledge, the method was extended by applying Chl-FI, which adds information of the anthocyanins spatial distribution within the whole grape bunches (Agati et al. 2008). The power of Chl-FI in predicting physiological disorders presymptomatically was illustrated by Lötze et al. (2006) in a study on preharvest detection of bitter pit in apple fruit and by Delalieux et al. (2009) to detect scab-induced stress in apple leaves. An excellent review on applications of Chl-FI in horticultural research till 2012 is provided by Gorbe and Calatayud (2012). In this review, the attention is given to the use of Chl-FI for the detection of abiotic and biotic stresses during crop cultivation, during postharvest life of fruits and flowers, and Chl-FI as phenotyping tool in screening of genotypes. The use of Chl-FI as a high throughput screening in crop improvement is also highlighted by Harbinson et al. (2012). Chl-FI has been used to evaluate chicory seed maturity (Ooms and Destain 2011), as diagnostic technique to predict compatibility in grafted plants (Calatayud et al. 2013), to facilitate breeding of lettuce cultivars (Bauriegel et al. 2014), to study decay of fresh-cut lettuce (Simko et al.
2015), for nondestructive phenotyping of lettuce plants (Simko et al. 2016), in monitoring minimal processing and warm water treatments of fresh-cut salads (Hägele et al. 2016), and in early detection of fungal infection of stored apple fruit (Pieczywek et al. 2018). Detection of plant diseases by imaging sensors and their application in precision agriculture and plant phenotyping has been reviewed by Mahlein (2016). An important issue in agriculture is the assessment of seed quality. In a recent paper, Galletti et al. (2020) have explored the combination of Chl-FI and chemometrics-based multispectral imaging to characterize seed quality of Solanum lycopersicum L. and Daucus carota L.

A major challenge in assessing quality control and analysis of physiological states, based on photosynthetic characteristics, is imaging of non-flat samples (Ciscato 2000). The images are subjected to vignetting, a phenomenon of signal intensity fading out towards the image periphery. In comprehensive work on quality assessment of fruits and vegetables and on pre- and postharvest stress in fruit trees and apples with Chl-FI, the images were processed by applying a mask after initial cropping, background subtraction, and intensity correction (Fig. 3). From the resulting images, several fluorescence parameters were calculated pixel by pixel. To enhance visualization and highlight details of the image, a false colour (SA-Pseudo colour scale, KhorosPro2001) was applied (Figs. 4, 5, 6) (Ciscato 2000, Huybrechts 2003). This approach was used in a study to detect the occurrence of an internal disorder (bitter pit) in Golden Delicious apples before symptoms became visible at the surface (Figs. 5, 6) (Huybrechts 2003, Lötze et al. 2006). A following step in the image processing is the calculation of the histogram and cumulative distribution function of the pixel values. Fig. 7 shows an example of the pixel distribution of maximal fluorescence of selected individual fruits and its weighted average. The heterogeneity between samples is more explicit in samples developing the physiological disorder (Ciscato et al. 2001, Huybrechts 2003).

Recently, a new Chl-FI approach using structured illumination coupled with a proposed automated method for correcting vignetting of $\mathrm{Chl}$ fluorescence images is discussed by Lu and Lu (2020). They applied this new approach for the detection of chilling injury in cucumbers.

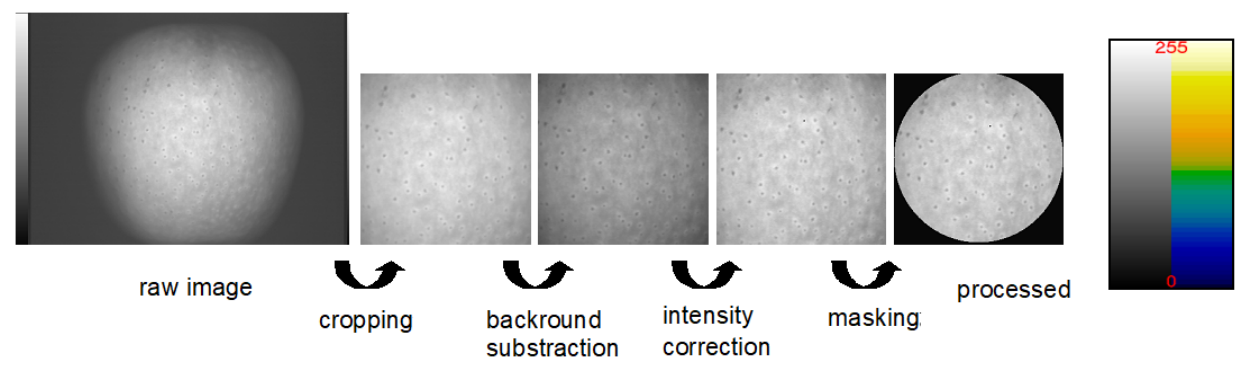

Fig. 3. Image processing. To minimize the curvature effect of the apple, the raw image is cropped. The image is further processed by background subtraction, intensity correction, and a mask is applied. Of the 65,536 pixels of the image, 51,431 are used $\left(8.04 \mathrm{~cm}^{2}\right)$. The other pixels belong to the mask. To enhance visualization, false colour (SA-Pseudo colour scale, KhorosPro2001) was applied (Ciscato 2000, Huybrechts 2003). 


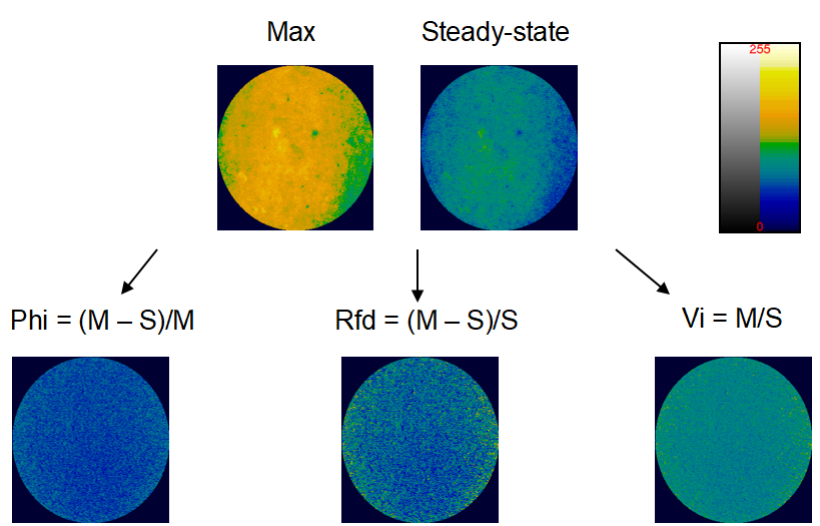

Fig. 4. Upper row: maximum and steady state fluorescence images. Lower row: pixel by pixel calculated fluorescence parameters. Sample: apple cv. Jonagold (Huybrechts 2003). Phi - Genty parameter $\phi_{\mathrm{PSII}}=\left(\mathrm{F}_{\mathrm{M}^{\prime}}-\mathrm{F}_{\mathrm{t}}\right) / \mathrm{F}_{\mathrm{M}}{ }^{\prime} ; \mathrm{Rfd}-$ fluorescence decrease ratio (Lichtenthaler and Babani 2000); Vi - indicator of photosynthetic quantum conversion (Lichtenthaler and Babani 2000). SA-Pseudo-colour scale (KhorosPro2001).

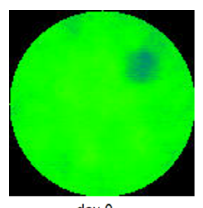

day 0
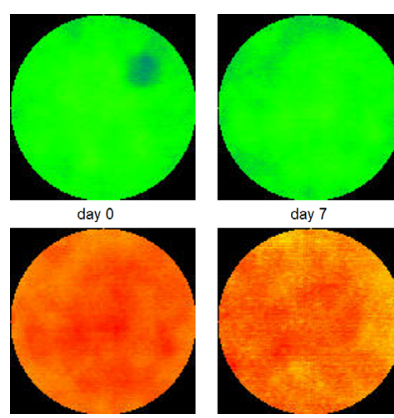

day 7

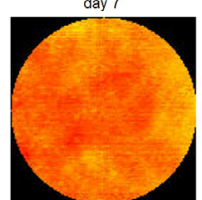

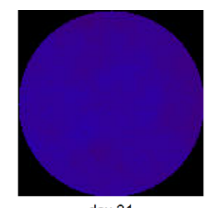

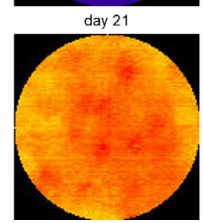

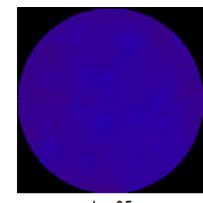
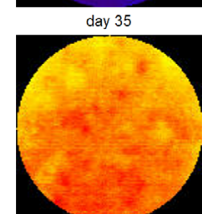

Fig. 5. Image analysis of a Golden Delicious apple measured at harvest (day 0) and followed until $35 \mathrm{~d}$ after storage. Upper row: 8-bit images of maximal fluorescence (M). Lower row: 32-bit M-images. Changes in pixel intensity distribution reflect senescence. This apple did not develop bitter pit (by courtesy of R. Valcke, see also Huybrechts 2003, Lötze et al. 2006).

For more information on the use of different sensors, including fluorescence tools, to assess quality of fruits and vegetables see Agati et al. (2020).

\section{Ecosystems}

Fluctuations in light intensities during the day, from sunrise to sunset, changing cloud densities, crown composition of trees, and plants growing under canopies, leaves are able to adapt their physiological status in short time windows or over longer periods. Tree-crown leaves exhibit a gradient from the bottom of the crown towards the top which can be considered as a gradual transition from 'shade to sun' leaves. Extensive studies on the photosynthetic activity using Chl-FI of sun and shade leaves have been performed by Lichtenthaler et al. (2007a,b and references therein). Besides the sun-shade topic, the phenomenon of patchy
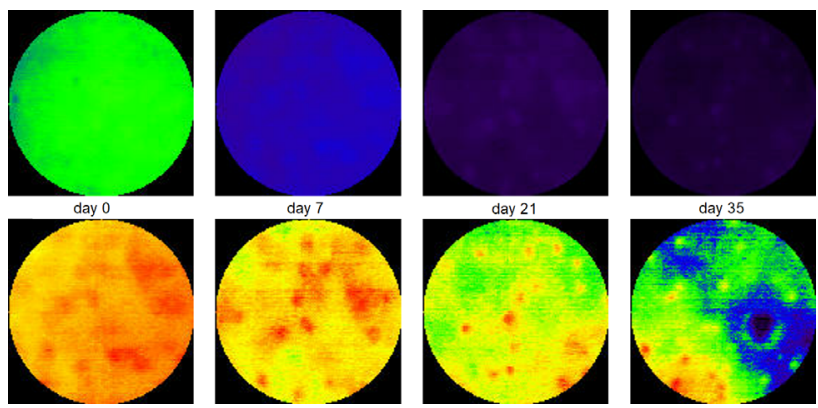

Fig. 6. Fluorescence image analysis of a Golden Delicious apple which developed bitter pit after storage. Upper row: 8-bit M-images. Lower row: 32-bit M-images. Changes in pixel distribution reflect the combined effect of senescence and the occurrence of the physiological disorder (by courtesy of R. Valcke, see also Huybrechts 2003, Lötze et al. 2006).

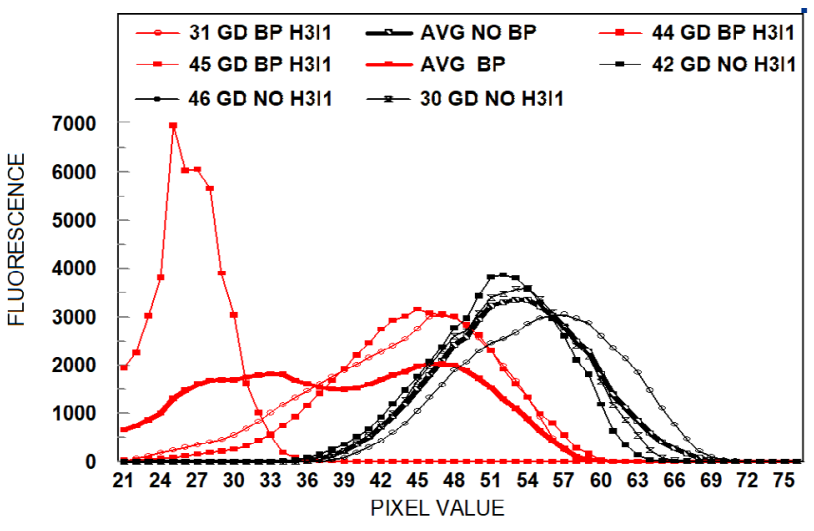

Fig. 7. Golden Delicious apple: pixel distribution of maximal fluorescence of selected individual fruits (see number, fine curves) and its weighted average (bold curves). Black curves: no bitter pit (BP) present, red curves: fruit with bitter pit. $\mathrm{H} 3 / 1$ : code harvest. (by courtesy of R. Valcke, see also Huybrechts 2003, Lötze et al. 2006).

stomatal closure in heterobaric leaves, in which vertical extensions of bundle sheath cells delimit the mesophyll and restrict the diffusion of $\mathrm{CO}_{2}$, was studied by Kamakura et al. (2012). The distribution of PSII quantum yield $\left(\Phi_{\text {II }}\right)$ obtained from Chl-FI revealed fluorescent patches only during the day with the low stomatal conductance. A numerical simulation of leaf gas-exchange and Chl-FI showed a heterogeneous distribution of electron transport rate through PSII with a bimodal kinetic under both natural and saturated photosynthetic photon flux densities. Using a 'Light-Induced Fluorescence Transient (LIFT) Device' (version LIFT-REM, Soliense Inc., New York, USA) the photosynthetic interaction with fluctuating environment and canopy architecture over two seasons was studied by Keller et al. (2019). They showed that the quantum efficiency of PSII was not only affected by the light intensity but also by spectral indices representing canopy structure effects. 
The impact of climate change on photosynthetic efficiency and energy partitioning was investigated by Song et al. (2016). In this study, Stipa bungeana was subjected to different thermal regimes and water conditions in controlled chambers. Chl-FI provided detailed information on the spatial heterogeneity of Chl fluorescence parameters and improved the analysis of photosynthetic performance under various temperature and water conditions. Using a modified PAM-imaging instrument, Leal et al. (2015) quantified the distribution of photochemical activity, Chl $a$ content and GFPs simultaneously in symbiotic cnidarians.

To investigate the possible benefit of elevated air temperature and drought stress, grassland species like Rumex acetosa were grown in model ecosystems consisting of 12 sunlit, climate-controlled chambers (Gielen et al. 2005, 2007b). During the autumn period, frequent measurements of digital photography to estimate the relative degree of senescence, Chl fluorescence transients, and Chl-FI were made. After an initial positive treatment effect of a $3^{\circ} \mathrm{C}$ temperature increase, this effect disappeared over a three-year period, meaning that the plants did not photosynthetically acclimated to this temperature increase. Moreover, air temperature $\left(\mathrm{T}_{\text {air }}\right) \times$ species $(\mathrm{S})$ interactions could be important in conditions of severe drought stress.

\section{Sun-induced fluorescence}

Sensing Chl fluorescence from a distance was already well-established in aquatic science since the early 1960 s (for a review see Gower 2016). Recently, Erickson et al. (2019) used an aircraft-mounted 'Portable Remote Imaging SpectroMeter' (PRISM) to establish vertical fluorescence profiles of phytoplankton in the upper $10 \mathrm{~m}$ of a marine environment. Remote sensing of Chl fluorescence became an important endeavor in terrestrial research (for a review see Frankenberg and Berry 2018). The remote-sensed Chl fluorescence relies on passive measurement of sun-induced fluorescence (SIF) instead of active excitation light. These passive airborne imaging sensors include hyperspectral imaging systems able to retrieve discrete emission bands and the full emission spectrum with high spatial resolution for field applications (Rascher et al. 2015, Pinto et al. 2016, 2017; Frankenberg et al. 2018, Siegmann et al. 2019, Du et al. 2020). To detect the weak SIF signal from vegetation canopy against a strong background reflectance, very high-resolution sensors are required. Satellite image analysis, such as band ratio, Fraunhofer Line Depth (FLD), 2FLD, 3FLD, and modified FLD are used to retrieve SIF (Meroni et al. 2009). To estimate spatial SIF, the empirical relationship between simulated Canopy Chlorophyll Concentration (CCC) and simulated SIF, several modelling systems has been applied (Verrelst et al. 2017). A recent study presenting new approaches to estimate spatial SIF can be found in Sinha et al. (2020) and on quantifying vegetation biophysical parameters in De Grave et al. (2020). For the reader interested in the topic of remote sensing of solar-induced Chl fluorescence, I recommend the excellent review of Mohammed et al. (2019). Also, the reader can consult special issues of the journal Remote Sensing: 'Remote Sensing of Vegetation
Fluorescence and Photosynthetic Efficiency' (Moreno 2017) and 'Advances on Quantitative Remote Sensing of Sun-induced Chlorophyll Fluorescence' (Cogliati et al. 2020).

\section{Combinations of hyperspectral, multispectral, and thermal imaging}

In recent years, multispectral imaging is being explored to assess growth patterns, physiological and quality parameters. Visible features, such as colour, surface topography, morphology, size, and growth patterns, are determined by machine vision based on RGB (red, green, blue) cameras. Near-infrared spectroscopy (NIR) can be used for the determination of chemical composition. Hyperspectral imaging combines the two techniques and delivers information on both spatial and spectral aspects. More information on this type of multispectral imaging can be found in the review paper of Boelt et al. (2018).

Combination of thermography and Chl-FI was explored in studies on biotic stress, such as the impact of Fusarium culmorum on photosynthetic integrity (Bauriegel et al. 2011), detection and quantification of apple scab (Belin et al. 2013), viral infection in sweet potato (Wang et al. 2019), and stress induced by Rosellinia necatrix in avocado plants (Granum et al. 2015). On the other hand, hyperspectral imaging was combined with Chl-FI to detect decay in fresh-cut lettuce (Simko et al. 2015), in the nondestructive quantitative determination of shikimic acid in transgenic maize exhibiting glyphosate tolerance (Feng et al. 2018), and in the identification of spatial patterns off photosynthesis hotspots in moss- and lichen-dominated soil (Kleefeld et al. 2018).

To assess diurnal canopy temperature dynamics and desiccation stress management of two tree species, Taria et al. (2020) combined infrared and Chl-FI with a phenomic approach. In this study, IR imaging was performed in the field, while Chl-FI measurements were done on detached leaves in the laboratory. The separate measurements performed under different conditions can complicate the interpretation of physiological results.

Hyperspectral reflectance and Chl-FI revealed the presence of scab stress in apple leaves before symptoms became visible with the naked eye (Delalieux et al. 2009). Early stages of the infection were characterized by low PSII quantum efficiency attended by low narrow waveband $\mathrm{R}_{1480} / \mathrm{R}_{2135}$ index values, while a high overall reflectance in the VIS and SWIR spectra domains indicated a severe, well developed scab infection. A further combination of VIS/NIR hyperspectral reflectance and Chl-FI capabilities mounted on a semi-autonomous cart for use in outdoor fields, was developed by Lefcourt et al. (2017). A study on Fusarium head blight on wheat spikelets using thermal imaging, Chl-FI, and hyperspectral imaging was performed by Mahlein et al. (2019). The three imaging systems were operated as separate units instead of being combined into one unit. Features of fluorescence, thermography, and reflectance were analysed in a study on in-planta uptake of herbicides and their microbial degradation (Chaerle et al. 2003). The same 'robotized time-lapse imaging system', 
in which the different cameras were integrated into an automated imaging system, was used in studies on a plantvirus interaction between resistant tobacco and Tobacco mosaic virus (TMV; Chaerle et al. 2004) and for the plantfungus system of sugar beet-Cercospora beticola (Chaerle et al. 2007). In a review paper, Lenk et al. (2007) discussed possible applications of the combination of multispectral fluorescence and reflectance imaging on leaf and fruit level. Recently, this three-imaging approach has been used in a model plant-pathogen system of lettuce-Rhizoctomia solani (Sandmann et al. 2018). Combinations of blue-green fluorescence and thermal imaging for an early detection of pathogen infection in sunflower has been used by OrtizBustos et al. (2017). Yao et al. (2018) used multicolour fluorescence imaging combined with kinetic Chl-FI to phenotype Arabidopsis responses to drought stress.

\section{Image processing - statistical analysis}

An important challenge is how to interpret fluorescence images. A proper analysis of the images requires an understanding of how $\mathrm{Chl}$ fluorescence is imaged. Moreover, Chl fluorescence variables are usually not normally distributed (Lazár and Nauš 1998). One of the first papers mentioning routines for analysis of fluorescence images was written by Fenton and Crofts (1990). They used a software program, the FVIPS, 'fluorescence video image processing software'. A state of the art of the image processing applied on Chl fluorescence images before 2004 can be found in Nedbal and Whitmarsh (2004) and Oxborough (2004). Since then, several approaches to analyze the images has been used. Lichtenthaler et al. (2005) performed a pre-processing on the images, while Codrea et al. (2004a,b), in a study on quality assessment apples, designed a neural network based on automatic classification system using global features from texture analysis. Berger et al. (2007) identified unique fluorescence features by advanced statistical analysis of the fluorescence images, while Cruz et al. (2016) used ImageJ to calculate and visualize photosynthetic parameters across selected regions of interest (ROI).

In a series of studies, to analyse quantitatively Chl fluorescence images, Gielen et al. (2005, 2006, 2007a) applied advanced statistical and image-processing approaches. Several properties describing frequency distribution of pixel values of the hue stack were used to analyse the images obtained from grassland species subjected to different air temperatures (Gielen et al. 2005). In a study on ozone-stressed rape, each image was reduced to a set of 21 features, of which five were descriptors of the image histogram and the remaining 16 were extracted by common texture analysis techniques used in image classification (Gielen et al. 2006). In their study on the effect of chronic ozone exposure on beech trees and its impact on leaf senescence, image processing was performed with Matlab Image Processing Toolbox (The MathWorks, Inc., Natick, USA) (Gielen et al. 2007a). In a study to predict bitter pit in apple before any symptoms were visible, Lötze et al. (2006) used cumulative distribution functions which describe fluorescence distribution in terms of relative frequency as a mathematical function [R-statistics ( $R$-gui) and Statistical Analysis System (SAS) (SAS Institute Inc., USA) programs were used to analyse the data].

An extensive approach for data analysis is described by Cen et al. (2017) in a study using Chl-FI to uncover photosynthetic fingerprint of a citrus disease (Huanglongbing). They started from 26 images per leaf sample related to fluorescence quenching obtained from kinetic Chl fluorescence imaging. Several fluorescence parameters were calculated by averaging the intensity of region of interest (ROI). From these fluorescence parameters, feature selection methods including random frog (RF) (Sun et al. 2020), sequential forward selection (SFS) (Marcano-Cedeño et al. 2010), and Monte Carlo uninformative variable elimination (MC-UVE) (Han et al. 2008) were used. Principal component analysis (PCA) was further applied to reduce the dimension of the image cubes and to obtain an uncorrelated orthogonal basis set from the original image set. For further details on the data analysis and the results, see this paper of Cen et al. (2017). Classification methods based on imaging data to detect bacterial infection in melon plants were described by Pineda et al. (2018). In a study on 'salt overly sensitive' (sos) mutants of Arabidopsis thaliana to drought stress, Sun et al. (2019) applied a time-series deep-learning algorithm, sparse auto encodes (SAEs) neural network, to extract time series $\mathrm{Chl}$ fluorescence features which were used in four classification models: linear discriminant analysis (LDA) (McLachlan 2004), k-nearest neighbor classifier (KNN) (Shakhnarovich et al. 2005), Gaussian naïve Bayes (NB) (Marin and Robert 2014), and support vector machine (SVM) (Cristianini and Shawe-Taylor 2000). At last, an interesting review paper by Rousseau et al. (2015b) discussed multispectral imaging of plants. They highlighted not only several multiple scale highresolution imaging techniques in plant sciences, but also multiscale image processing tools, such as wavelets, fractals, and variants, on these methods of analysis which are available under the free and open software of ImageJ.

\section{Conclusions}

Surfing through the papers mentioned in the several paragraphs in this review, it may be quite straightforward that Chl-FI, as applied in the different domains, fulfils the condition of making the 'invisible visible' on different structural levels of plants - cell, leaf, whole plant, and canopy. Further progress in highresolution and fast-camera technology and multiple image processing techniques, statistical analysis, artificial intelligence, and big-data analytics, will further improve the extraction of hidden information and provide new insights into the whole range of physiological processes. Furthermore, technologies for remote sensing of plant phenotypes using satellite of UAV platforms are rapidly expanding. An oncoming program to monitor the global steady-state chlorophyll fluorescence in terrestrial vegetation is the 'Fluorescence Explorer' (FLEX) mission by the European Space Agency (ESA, see: https://earth.esa. 
int/eogateway/missions/flex).

An important domain, which was not attended in this review, is forensic research. A major issue in this field is the discovery and recovery of buried human bodies, especially under forest canopies. Using plants as environmental sentinels and UAVs equipped with remote sensing techniques, forensic investigators should be able to make better-informed decisions. Brabazon et al. (2020) discussed the possibility to use plants to detect human decomposition. There is no doubt that, besides monitoring spectral features, Chl-FI and multicolour fluorescence imaging will play an important role in the further exploration in forensic research.

Since the initial work of pioneers like Omasa and his co-workers, who published for the first time the potential of Chl-FI and Lichtenthaler and his group with Chl-FI and multicolour fluorescence imaging, the current capability to image large areas in order to understand the heterogeneity of the fluorescence signals over these areas would not be possible. A crossover with the progress in other imaging approaches such as hyperspectral and thermal imaging and in tremendous availability of data analysis methods, will result in further expansion in plant research.

\section{References}

Agati G., Bilger W., Cerovic Z.G.: Fluorescence tools for sensing of quality related phytochemicals in fruits and vegetables. In: Kuswandi B., Siddiqui M.W. (ed.): Sensor-Based Quality Assessment Systems for Fruits and Vegetables. Pp. 79-109. Apple Academic Press, New York 2020.

Agati G., Cerovic Z.G., Moya I.: The effect of decreasing temperature up to chilling values on the in vivo F685/F735 chlorophyll fluorescence ratio in Phaseolus vulgaris and Pisum sativum. The role of photosystem I contribution to the $735 \mathrm{~nm}$ fluorescence band. - Photochem. Photobiol. 72: $75-84,2000$

Agati G., Meyer S., Matteini P., Cerovic Z.G.: Assessment of anthocyanins in grape (Vitis vinifera L.) berries using a noninvasive chlorophyll fluorescence method. - J. Agr. Food Chem. 55: 1053-1061, 2007.

Agati G., Traversi M.L., Cerovic Z.G.: Chlorophyll fluorescence imaging for the noninvasive assessment of anthocyanins in whole grape (Vitis vinifera L.) bunches. - Photochem. Photobiol. 84: 1431-1434, 2008.

Ammer K., Ring F.: The history of thermal imaging from 1960.In: Ammer K., Ring F. (ed.): The Thermal Human Body: A Practical Guide to Thermal Imaging. Jenny Stanford Publishing, Boca Raton 2019.

Awlia M., Nigro A., Fajkus J. et al:: High-throughput nondestructive phenotyping of traits that contribute to salinity tolerance in Arabidopsis thaliana. - Front. Plant Sci. 7: 1414, 2016.

Barbagallo R.P., Oxborough K., Pallett K.E., Baker N.R.: Rapid, noninvasive screening for perturbations of metabolism and plant growth using chlorophyll fluorescence imaging. - Plant Physiol. 132: 485-493, 2003.

Barták M., Hájek J., Vráblíková H., Dubová J.: High-light stress and photoprotection in Umbilicaria antarctica monitored by chlorophyll fluorescence imaging and changes in zeaxanthin and glutathione. - Plant Biol. 6: 333-341, 2004.

Bauriegel E., Brabandt H., Gärber U., Herppich W.B.: Chlorophyll fluorescence imaging to facilitate breeding of Bremia lactucae-resistant lettuce cultivars. - Comput. Electron. Agr. 105: 74-82, 2014

Bauriegel E., Giebel A., Herppich W.B.: Hyperspectral and chlorophyll fluorescence imaging to analyse the impact of Fusarium culmorum on the photosynthetic integrity of infected wheat ears. - Sensors-Basel 11: 3765-3779, 2011

Bayçu G., Moustaka J., Gevrek N., Moustakas M.: Chlorophyll fluorescence imaging analysis for elucidating the mechanism of photosystem II acclimation to cadmium exposure in the hyperaccumulating plant Noccaea caerulescens. - Materials 11: 2580,2018

Belin É., Rousseau D., Boureau T., Caffier V.: Thermography versus chlorophyll fluorescence imaging for detection and quantification of apple scab. - Comput. Electron. Agr. 90: 159-163, 2013.

Bellasio C., Olejníčková J., Tesař R. et al.: Computer reconstruction of plant growth and chlorophyll fluorescence emission in three spatial dimensions. - Sensors-Basel 12: 1052-1071, 2012.

Berger S., Benediktyová Z., Matouš K. et al.: Visualization of dynamics plant-pathogen interaction by novel combination of chlorophyll fluorescence imaging and statistical analysis: differential effects of virulent and avirulent strains of P. syringae and of oxylipins on A. thaliana. - J. Exp. Bot. 58: 797-806, 2007.

Bielczynski L.W., Łącki M.K., Hoefnagels I. et al.: Leaf and plant age affects photosynthetic performance and photoprotective capacity. - Plant Physiol. 175: 1634-1648, 2017.

Boelt B., Shrestha S., Salimi Z. et al.: Multispectral imaging a new tool in seed quality assessment? - Seed Sci. Res. 28: 222-228, 2018.

Borek M., Baçzek-Kwinta R., Rapacz M.: Photosynthetic activity of variegated leaves of Coleus $\times$ hybridus hort. cultivars characterized by chlorophyll fluorescence techniques. Photosynthetica 54: 331-339, 2016.

Borsuk A.M., Brodersen C.R.: The spatial distribution of chlorophyll in leaves. - Plant Physiol. 180: 1406-1417, 2019.

Brabazon H., DeBruyn J.M., Lenaghan S.C. et al.: Plants to remotely detect human decomposition? - Trends Plant Sci. 25: 947-949, 2020.

Bramley R.G.V.: Understanding variability in winegrape production systems. 2. Within vineyard variation in quality over several vintages. - Aust. J. Grape Wine Res. 11: 33-42, 2005.

Bresson J., Vasseur F., Duazat M. et al.: Quantifying spatial heterogeneity of chlorophyll fluorescence during plant growth and in response to water stress. - Plant Methods 11: 23, 2015.

Briantais J.-M., Merkelo H., Govindjee: Lifetime of the excited state in vivo. III. Chlorophyll during fluorescence induction in Chlorella pyrenoidosa. - Photosynthetica 6: 133-141, 1972.

Bro L., Meyer S., Genty B.: Heterogeneity of leaf $\mathrm{CO}_{2}$ assimilation during photosynthetic induction. - Plant Cell Environ. 19: 1349-1358, 1996.

Buschmann C., Lichtenthaler H.K.: Principles and characteristics of multi-colour fluorescence imaging of plants. - J. Plant Physiol. 152: 297-314, 1998.

Calatayud A. Roca D., Martínez P.F.: Spatial-temporal variations in rose leaves under water stress conditions studied by chlorophyll fluorescence imaging. - Plant Physiol. Bioch. 44: 564-573, 2006.

Calatayud A., San Bautista A., Pascual B. et al.: Use of chlorophyll fluorescence imaging as diagnostic technique to predict compatibility in melon graft. - Sci. Hortic.-Amsterdam 149: 13-18, 2013

Carreira C., Staal M., Middelboe M., Brussaard C.P.D.: Autofluorescence imaging system to discriminate and quantify the 
distribution of benthic cyanobacteria and diatoms. - Limnol. Oceanogr. Methods 13: 169-177, 2015.

Castrisios K., Martin A., Müller M.N. et al:: Response of Antarctic sea-ice algae to an experimental decrease in $\mathrm{pH}$ : a preliminary analysis of chlorophyll fluorescence imaging of melting ice. - Polar Res. 37: 1438696, 2018.

Cen H., Weng H., Yao J. et al.: Chlorophyll fluorescence imaging uncovers photosynthetic fingerprint of citrus Huanglongbing.Front. Plant Sci. 8: 1509, 2017.

Chaerle L., Hagenbeek D., De Bruyne E. et al.: Thermal and chlorophyll fluorescence imaging distinguish plant-pathogen interactions at an early stage. - Plant Cell Physiol. 45: 887896, 2004.

Chaerle L., Hagenbeek D., De Bruyne E., Van Der Straeten D.: Chlorophyll fluorescence imaging for disease-resistance screening of sugar beet. - Plant Cell Tiss. Org. 91: 97-106, 2007.

Chaerle L., Hulsen K., Hermans C. et al.: Robotized time-lapse imaging to assess in-planta uptake of phenylurea herbicides and their microbial degradation. - Physiol. Plantarum 118: 613-619, 2003.

Chen C.P., Frank T.D., Long S.P.: Is a short, sharp shock equivalent to long-term punishment? Contrasting the spatial pattern of acute and chronic ozone damage to soybean leaves via chlorophyll fluorescence imaging. - Plant Cell Environ. 32: 327-335, 2009.

Chen F.-E., Wu N., Zhang Z.-W. et al.: Perspective of monitoring heavy metals by moss visible chlorophyll fluorescence parameters. - Front. Plant Sci. 10: 35, 2019.

Ciscato M.: Development of a fluorescence imaging system for the quality assessment of fruit and vegetables. Ph.D. Thesis. UHasselt, D/2000/2451/125, 2000.

Ciscato M., Sowinska M., vandeVen M. et al.: Fluorescence imaging as a diagnostic tool to detect physiological disorders during storage of apples. - Acta Hortic. 553: 507-512, 2001.

Ciscato M., Valcke R.: Chlorophyll fluorescence imaging of heavy metal stress treated plants. - In: Garab G. (ed.): Photosynthesis: Mechanisms and Effects. Vol. IV. Pp. 26612663. Springer, Dordrecht 1998.

Codrea M.C., Nevalainen O.S., Huybrechts C. et al.: Classification of apples according to physiological status measured by fluorescence imaging. TUCS Technical Reports 646 . Turku Centre for Computer Science, Turku 2004b.

Codrea M.C., Nevalainen O.S., Tyystjärvi E. et al.: Classifying apples by means of fluorescence imaging. - Int. J. Pattern Recogn. Artif. Intell. 18: 157-174, 2004a.

Cogliati S., Alonso L., Zhao F. (ed.): Remote Sensing - Special Issue: 'Advances on Quantitative Remote Sensing of Suninduced Chlorophyll Fluorescence', 2020.

Cristianini N., Shawe-Taylor J.: An Introduction to Support Vector Machines and Other Kernel-based Learning Methods. Pp. 189. Cambridge University Press, Cambridge 2000.

Croxdale J.G., Omasa K.: Chlorophyll $a$ fluorescence and carbon assimilation in developing leaves of light-grown cucumber. Plant Physiol. 93: 1078-1082, 1990a.

Croxdale J.G., Omasa K.: Patterns of chlorophyll fluorescence kinetics in relation to growth and expansion in cucumber leaves. - Plant Physiol. 93: 1083-1088, 1990b.

Cruz J.A., Savage L.J., Zegarac R. et al.: Dynamic environmental photosynthetic imaging reveals emergent phenotypes. - Cell Systems 2: 365-377, 2016.

Cséfalvay L., Di Gaspero G., Matouš K. et al.: Pre-symptomatic detection of Plasmopara viticola infection in grapevine leaves using chlorophyll fluorescence imaging. - Eur. J. Plant Pathol. 125: 291-302, 2009.

Daley P.F., Raschke K., Ball J.T., Berry J.A.: Topography of photosynthetic activity of leaves obtained from video imaging of chlorophyll fluorescence. - Plant Physiol. 90: 1233-1238, 1989.

De Grave C., Verrelst J., Morcillo-Pallarés P. et al.: Quantifying vegetation biophysical variables from the Sentinel-3/FLEX tandem mission: Evaluation of the synergy of OLCI and FLORIS data sources. - Remote Sens. Environ. 251: 112101, 2020.

de Sousa C.A.F., de Paiva D.S., Casari R.A. et al.: A procedure for maize genotypes discrimination to drought by chlorophyll imaging rapid light curves. - Plant Methods 13: 61, 2017.

Delalieux S., Auwerkerken A., Verstraeten W.W. et al.: Hyperspectral reflectance and fluorescence imaging to detect scab induced stress in apple leaves. - Remote Sens.-Basel 1: 858874, 2009.

Devacht S., Lootens P., Baert J. et al.: Evaluation of cold stress of young industrial chicory (Cichorum intybus L.) by chlorophyll fluorescence imaging. I. Light induction curve. Photosynthetica 49: 161-171, 2011.

Dong Z., Men Y., Li Z. et al.: Chlorophyll fluorescence imaging as a tool for analyzing the effects of chilling injury on tomato seedlings. - Sci. Hortic.-Amsterdam 246: 490-497, 2019.

Dong Z., Men Y., Liu Z. et al.: Application of chlorophyll fluorescence imaging technique in analysis and detection of chilling injury of tomato seedlings. - Comput. Electron. Agr. 168: 105109, 2020.

Du S., Liu L., Liu X. et al.: The solar-induced chlorophyll fluorescence imaging spectrometer (SIFIS) on board the First Terrestrial Ecosystem Carbon Inventory Satellite (TECIS-1): specifications and prospects. - Sensors-Basel 20: 815, 2020.

Duan J., Fu B., Kang H. et al.: Response of gas-exchange characteristics and chlorophyll fluorescence to acute sulfur dioxide exposure in landscape plants. - Ecotox. Environ. Safe. 171: 122-129, 2019.

Ehlert B., Hincha D.K.: Chlorophyll fluorescence imaging accurately quantifies freezing damage and cold acclimation responses in Arabidopsis leaves. - Plant Methods 4: 12, 2008.

Ellenson J.L., Amundson R.G.: Delayed light imaging for the early detection of plant stress. - Science 215: 1104-1106, 1982.

Endo R., Omasa K.: Chlorophyll fluorescence imaging of individual algal cells: effects of herbicide on Spirogyra distenta at different growth stages. - Environ. Sci. Technol. 38: 4165-4168, 2004

Endo R., Omasa K.: 3-D cell-level chlorophyll fluorescence imaging of ozone-injured sunflower leaves using a new passive light microscope system. - J. Exp. Bot. 58: 765-772, 2007.

Erickson Z.K., Frankenberg C., Thompson D.R. et al.: Remote sensing of chlorophyll fluorescence in the ocean using imaging spectrometry: toward a vertical profile of fluorescence. Geophys. Res. Lett. 46: 1571-1579, 2019.

Feng X., Yu C., Chen Y. et al.: Non-destructive determination of shikimic acid concentration in transgenic maize exhibiting glyphosate tolerance using chlorophyll fluorescence and hyperspectral imaging. - Front. Plant Sci. 9: 468, 2018.

Fenton J.M., Crofts A.R.: Computer aided fluorescence imaging of photosynthetic systems. - Photosynth. Res. 26: 59-66, 1990.

Fernandez-Jaramillo A.A., Duarte-Galvan C., Contreras-Medina L.M. et al.: Instrumentation in developing chlorophyll fluorescence biosensing: a review. - Sensors-Basel 12: 11853$11869,2012$.

Fortunato A.A., Debona D., Aucique-Pérez C.E. et al.: Chlorophyll $a$ fluorescence imaging of soya bean leaflets infected by Corynespora cassiicola. - J. Phytopathol. 166: 
782-789, 2018

Frankenberg C., Berry J.: Solar induced chlorophyll fluorescence: origins, relation to photosynthesis and retrieval. - Compr. Remote Sens. 3: 143-162, 2018.

Frankenberg C., Köhler P., Magney T.S. et al.: The chlorophyll fluorescence imaging spectrometer (CFIS), mapping far red fluorescence from aircraft. - Remote Sens. Environ. 217: 523536, 2018.

GallettiP.A., Carvalho M.E.A., Hirai W.Y.etal.: Integrating optical imaging tools for rapid and non-invasive characterization of seed quality: tomato (Solanum lycopersicum L.) and carrot (Daucus carota L.) as study cases. - Front. Plant Sci. 11: 577581, 2020

Gashi B., Babani F., Kongjika E.: Chlorophyll fluorescence imaging of photosynthetic activity and pigment contents of the resurrection plants Ramonda serbica and Ramonda nathaliae during dehydration and rehydration. - Physiol. Mol. Biol. Pla. 19: 333-341, 2013.

Gauslaa Y., Solhaug K.A., Longinotti S.: Functional traits prolonging photosynthetic active periods in epiphytic cephalolichens during desiccation. - Environ. Exp. Bot. 141: 83-91, 2017.

Genty B., Briantais J.-M., Baker N.R.: The relationship between the quantum yield of photosynthetic electron transport and quenching of chlorophyll fluorescence. - BBA-Gen. Subjects 990: 87-92, 1989.

Genty B., Meyer S.: Quantitative mapping of leaf photosynthesis using chlorophyll fluorescence imaging. - Aust. J. Plant Physiol. 22: 277-284, 1995.

Gielen B., De Boeck H.J., Lemmens C.M.H.M. et al.: Grassland species will not necessarily benefit from future elevated air temperatures: a chlorophyll fluorescence approach to study autumn physiology. - Physiol. Plantarum 125: 52-63, 2005.

Gielen B., Löw M., Deckmyn G. et al.: Chronic ozone exposure affects leaf senescence of adult beech trees: a chlorophyll fluorescence approach. - J. Exp. Bot 58: 785-795, 2007a.

Gielen B., Naudts K., D'Haese D. et al:: Effects of climate warming and species richness on photochemistry of grasslands. - Physiol. Plantarum 131: 251-262, $2007 \mathrm{~b}$.

Gielen B., Vandermeiren K., Horemans N. et al.: Chlorophyll $a$ fluorescence imaging of ozone-stressed Brassica napus L. plants differing in glucosinolate concentrations. - Plant Biol. 8: 698-705, 2006.

Gilmore A.M., Govindjee: How higher plants respond to excess light: energy dissipation in photosystem II. - In: Singhal G.S., Renger G., Sopory S. et al. (ed.): Concepts in Photobiology. Pp. 513-548. Springer, Dordrecht 1999.

Goetz A.F.H.: Three decades of hyperspectral remote sensing of the earth: A personal view. - Remote Sens. Environ. 113: S5-S16, 2009.

Gorbe E., Calatayud A.: Applications of chlorophyll fluorescence imaging technique in horticultural research: a review. - Sci. Hortic.-Amsterdam 138: 24-35, 2012.

Govindjee: Sixty-three years since Kautsky: chlorophyll $a$ fluorescence. - Aust. J. Plant Physiol. 22: 131-160, 1995.

Gower J.: On the use of satellite-measured chlorophyll fluorescence for monitoring coastal waters. - Int. J. Remote Sens. 37: 2077-2086, 2016.

Granum E., Pérez-Bueno M.L., Calderón C.E. et al.: Metabolic responses of avocado plants to stress induced by Rosellinia necatrix analysed by fluorescence and thermal imaging. - Eur. J. Plant Pathol. 142: 625-632, 2015.

Gray G.R., Hope B.J., Qin X. et al.: The characterization of photoinhibition and recovery during cold acclimation in Arabidopsis thaliana using chlorophyll fluorescence imaging. - Physiol. Plantarum 119: 365-375, 2003.
Guadagno C.R., Ewers B.E., Speckman H.N. et al.: Dead or alive? Using membrane failure and chlorophyll $a$ fluorescence to predict plant mortality from drought. - Plant Physiol. 175: 223-234, 2017.

Guárdia M., Fernández J., Elena G., Fleck I.: Stomatal patchiness in the Mediterranean holm oak (Quercus ilex L.) under water stress in the nursery and in the forest. - Tree Physiol. 32: 829838, 2012.

Hacker J., Spindelböck P., Neuner G.: Mesophyll freezing and effects of freeze dehydration visualized by simultaneous measurement of IDTA and differential imaging chlorophyll fluorescence. - Plant Cell Environ. 31: 1725-1733, 2008.

Hägele F., Bauer S., Menegat A. et al.: Chlorophyll fluorescence imaging for monitoring the effects of minimal processing and warm water treatments on physiological properties and quality attributes of fresh-cut salads. - Food Bioprocess Technol. 9: 650-663, 2016.

Han Q.-J., Wu H.-L., Cai C.-B. et al.: An ensemble of Monte Carlo uninformative variable elimination for wavelength selection. - Anal. Chim. Acta 612: 121-125, 2008.

Harbinson J., Prinzenberg A.E., Kruijer W., Aarts M.G.M.: High throughput screening with chlorophyll fluorescence imaging and its use in crop improvement. - Curr. Opin. Biotech. 23: 221-226, 2012.

Harvey E.N.: A History of Luminescence from the Earliest Times until 1900. Pp. 692. American Philosophical Society, Philadelphia 1957.

Hawes I., Lund-Hansen L.C., Sorrell B.K. et al.: Photobiology of sea ice algae during initial spring growth in Kangerlussuaq, West Greenland: insights from imaging variable chlorophyll fluorescence of ice cores. - Photosynth. Res. 112: 103-115, 2012.

Herritt M.T., Pauli D., Mockler T.C., Thompson A.L.: Chlorophyll fluorescence imaging captures photochemical efficiency of grain sorghum (Sorghum bicolor) in a field setting. - Plant Methods 16: 109, 2020.

Hogewoning S.W., Harbinson J.: Insights on the development, kinetics, and variation of photoinhibition using chlorophyll fluorescence imaging of a chilled, variegated leaf. - J. Exp. Bot. 58: 453-463, 2007.

Holub O., Seufferheld M.J., Gohlke C. et al.: Fluorescence lifetime imaging (LFI) in real-time - a new technique in photosynthesis research. - Photosynthetica 38: 581-599, 2000.

Holub O., Seufferheld M.J., Gohlke C. et al.: Fluorescence lifetime imaging microscopy of Chlamydomonas reinhardtii: non-photochemical quenching mutants and the effect of photosynthetic inhibitors on the slow fluorescence transient. J. Microsc. 226: 90-120, 2007.

Humplík J.F., Lazár D., Husičková A., Spíchal L.: Automated phenotyping of plants shoots using imaging methods for analysis of plant stress responses - a review. - Plant Methods 11: 29, 2015.

Hupp S., Rosenkranz M., Bonfig K. et al.: Noninvasive phenotyping of plant-pathogen interaction: consecutive in situ imaging of fluorescing Pseudomonas syringae, plant phenolic fluorescence, and chlorophyll fluorescence in Arabidopsis leaves. - Front. Plant Sci. 10: 1239, 2019.

Huybrechts C.: The use of a fluorescence imaging system to study pre- and postharvest stress in fruit trees and apples. Ph.D. Thesis. UHasselt, D/2003/1942/9801, 2003.

Jedmowski C., Brüggemann W.: Imaging of chlorophyll fluorescence induction curve (OJIP) parameters, applied in a screening study with wild barley (Hordeum spontaneum) genotypes under heat stress. - J. Photochem. Photobiol. 151: 153-160, 2015. 
Kaiser Y.I., Menegat A., Gerhards R.: Chlorophyll fluorescence imaging: a new method for rapid detection of herbicide resistance in Alopecurus myosuroides. - Weed Res. 53: 399406, 2013.

Kalaji H.M., Goltsev V., Bosa K. et al.: Experimental in vivo measurements of light emission in plants: a perspective dedicated to David Walker. - Photosynth. Res. 114: 69-96, 2012.

Kamakura M., Kosugi Y., Takanashi S. et al.: Observation of the scale of patchy stomatal behavior in leaves of Quercus crispula using an imaging-PAM chlorophyll fluorometer. Tree Physiol. 32: 839-846, 2012.

Kasajima I.: Difference in oxidative stress tolerance between rice cultivars estimated with chlorophyll fluorescence analysis. BMC Res. Notes 10: 168, 2017.

Kautsky H., Hirsch A.: Neue Versuche zur Kohlensäureassimilation. - Naturwissenschaften 19: 964, 1931.

Keller B., Matsubara S., Rascher U. et al.: Genotype specific photosynthesis $\times$ environment interactions captured by automated fluorescence canopy scans over two fluctuating growing seasons. - Front. Plant Sci. 10: 1482, 2019.

Kleefeld A., Gypser S., Herppich W.B. et al.: Identification of spatial pattern of photosynthesis hotspots in moss- and lichendominated biological soil crusts by combining chlorophyll fluorescence imaging and multispectral BNDVI images. Pedobiologia 65: 1-11, 2018.

Kottuparambil S., Brown M.T., Park J. et al.: Comparative assessment of single and joint effects of diuron and Irgarol 1051 on Arctic and temperate microalgae using chlorophyll $a$ fluorescence imaging. - Ecol. Indic. 76: 304-316, 2017.

Kristoffersen A., Hamre B., Frette Ø., Erga S.R.: Chlorophyll $a$ fluorescence lifetime reveals reversible UV-induced photosynthetic activity in the green algae Tetraselmis. - Eur. Biophys. J. 45: 259-268, 2016.

Küpper H., Benedikty Z., Morina F. et al.: Analysis of OJIP chlorophyll fluorescence kinetics and $\mathrm{Q}_{\mathrm{A}}$ reoxidation kinetics by direct fast imaging. - Plant Physiol. 179: 369-381, 2019.

Lakowicz J.R.: Principles of Fluorescence Spectroscopy. $3^{\text {rd }}$ Edition. Pp. 954. Springer, Boston 2006.

Lawson T., Vialet-Chabrand S.: Chlorophyll fluorescence imaging. - In: Covshoff S. (ed.): Photosynthesis: Methods in Molecular Biology. Vol. 1770. Pp. 121-140. Humana Press, New York 2018

Lazár D., Nauš J.: Statistical properties of chlorophyll fluorescence induction parameters. - Photosynthetica 35: 121-127, 1998.

Leal M.C., Jesus B., Ezequiel J. et al.: Concurrent imaging of chlorophyll fluorescence, chlorophyll $a$ content and green fluorescent proteins-like proteins of symbiotic cnidarians. Mar. Ecol. 36: 572-584, 2015.

Lefcourt A.M., Kistler R., Gadsden S.A., Kim M.S.: Automated cart with VIS/NIR hyperspectral reflectance and fluorescence imaging capabilities. - Appl. Sci. 7: 3, 2017.

Lei R., Jiang H., Hu F. et al.: Chlorophyll fluorescence lifetime imaging provides new insight into the chlorosis induced by plant virus infection. - Plant Cell Rep. 36: 327-341, 2017.

Leipner J., Oxborough K., Baker N.R.: Primary sites of ozone-induced perturbations of photosynthesis in leaves: identification and characterization in Phaseolus vulgaris using high resolution chlorophyll fluorescence imaging. J. Exp. Bot. 52: 1689-1696, 2001.

Lenk S., Chaerle L., Pfündel E.E. et al.: Multispectral fluorescence and reflectance imaging at the leaf level and its possible applications. - J. Exp. Bot. 58: 807-814, 2007.

Li H., Wang P., Weber J.F., Gerhards R.: Early identification of herbicide stress in soybean (Glycine $\max (\mathrm{L}$.) Merr.) using chlorophyll fluorescence imaging technology. - SensorsBasel 18: 21, 2018.

Lichtenthaler H.K.: The Kautsky effect: 60 years of chlorophyll fluorescence induction kinetics. - Photosynthetica 27: 45-55, 1992.

Lichtenthaler H.K.: Multi-colour fluorescence imaging of photosynthetic activity and plant stress. - Photosynthetica 59: 364-380, 2021.

Lichtenthaler H.K., Ač A., Marek M.V. et al.: Differences in pigment composition, photosynthetic rates and chlorophyll fluorescence images of sun and shade leaves of four tree species. - Plant Physiol. Bioch. 45: 577-588, 2007 a.

Lichtenthaler H.K., Babani F.: Detection of photosynthetic activity and water stress by imaging the red chlorophyll fluorescence. - Plant Physiol. Bioch. 38: 889-895, 2000.

Lichtenthaler H.K., Babani F., Langsdorf G.: Chlorophyll fluorescence imaging of photosynthetic activity in sun and shade leaves of trees. - Photosynth. Res. 93: 235-244, 2007b.

Lichtenthaler H.K., Lang M., Sowinska M. et al.: Detection of vegetation stress via a new high resolution fluorescence imaging system. - J. Plant Physiol. 148: 599-612, 1996.

Lichtenthaler H.K., Lang M., Sowinska M. et al.: Uptake of the herbicide diuron (DCMU) as visualized by the fluorescence imaging technique. - Plant Biol. 110: 158-163, 1997.

Lichtenthaler H.K., Langsdorf G., Buschmann C.: Uptake of diuron and concomitant loss of photosynthetic activity in leaves as visualized by imaging the red chlorophyll fluorescence. - Photosynth. Res. 116: 355-361, 2013.

Lichtenthaler H.K., LangsdorfG., Lenk S., Buschmann C.: Chlorophyll fluorescence imaging of photosynthetic activity with the flash-lamp fluorescence imaging system. - Photosynthetica 43: 355-369, 2005.

Lichtenthaler H.K., Miehé J.A.: Fluorescence imaging as a diagnostic tool for plant stress. - Trends Plant Sci. 2: 316320, 1997

Lootens P., Devacht S., Baert J. et al.: Evaluation of cold stress of young industrial chicory (Cichorium intybus L.) by chlorophyll fluorescence imaging. II. Dark relaxation kinetics. - Photosynthetica 49: 185-194, 2011.

Lötze E., Huybrechts C., Sadie A. et al.: Fluorescence imaging as a non-destructive method for pre-harvest detection of bitter pit in apple fruit (Malus domestica Borkh.). - Postharvest Biol. Tec. 40: 287-294, 2006.

Lu Y., Lu R.: Enhancing chlorophyll fluorescence imaging under structural illumination with automated vignetting correction for detection of chilling injury in cucumbers. - Comput. Electron. Agr. 168: 105145, 2020.

Lyu J.I., Kim J.H., Chu H. et al.: Natural allelic variation of GVS1 confers diversity in the regulation of leaf senescence in Arabidopsis. - New Phytol. 221: 2320-2334, 2019.

Mahlein A.-K.: Plant disease detection by imaging sensors Parallels and specific demands for precision agriculture and plant phenotyping. - Plant Disease 100: 241-251, 2016.

Mahlein A.-K., Alisaac E., Al Masri A. et al.: Comparison and combination of thermal, fluorescence, and hyperspectral imaging for monitoring Fusarium head blight of wheat on spikelet scale. - Sensors-Basel 19: 2281, 2019.

Malkin S., Wong D., Govindjee, Merkelo H.: Parallel measurements on fluorescence lifetime and intensity changes from leaves during the fluorescence induction. - Photochem. Photobiophys. 1: 83-89, 1980.

Marcano-Cedeño A., Quintanilla-Domínguez J., Cortina-Januchs M.G., Andina D.: Feature selection using sequential forward selection and classification applying artificial metaplasticity neural network. IECON $2010-36^{\text {th }}$ Annual Conference on IEEE Industrial Electronics Society, Glendale, AZ, USA, 
2010. Pp. 2845-2850. IEEE 2010.

Marcek Chorvatova A.M., Uherek M., MateasikA., Chorvat Jr. D.: Time-resolved endogenous chlorophyll fluorescence sensitivity to $\mathrm{pH}$ : study on Chlorella sp. algae. - Methods Appl. Fluoresc. 8: 024007, 2020.

Marin J.-M., Robert C.P.: Bayesian Essentials with R. Pp. 296. Springer, New York 2014.

Massacci A., Nabiev S.M., Pietrosanti L. et al.: Response of the photosynthetic apparatus of cotton (Gossypium hirsutum) to the onset of drought stress under field conditions studied by gas-exchange analysis and chlorophyll fluorescence imaging. - Plant Physiol. Bioch. 46: 189-195, 2008.

Matsushima U., Kardjilov N., Hilger A. et al.: Visualization of water usage and photosynthetic activity of street trees exposed to $2 \mathrm{ppm} \mathrm{SO}_{2}-\mathrm{A}$ combined evaluation by cold neutron and chlorophyll fluorescence imaging. - Nucl. Instrum. Method. Phys. Res. A 605: 185-187, 2009.

McAusland L., Atkinson J.A., Lawson T., Murchie E.H.: High throughput procedure utilising chlorophyll fluorescence imaging to phenotype dynamic photosynthesis and photoprotection in leaves under controlled gaseous conditions. Plant Methods 15: 109, 2019.

McLachlan G.J.: Discriminant Analysis and Statistical Pattern Recognition. Pp. 526. Wiley Interscience, Hoboken 2004.

Méline V., Brin C., Lebreton G. et al.: A computation method based on the combination of chlorophyll fluorescence parameters to improve discrimination of visually similar phenotypes induced by bacterial virulence factors. - Front. Plant Sci. 11: 213, 2020.

Meng Q., Siebke K., Lippert P. et al.: Sink-source transition in tobacco leaves visualized using chlorophyll fluorescence imaging. - New Phytol. 151: 585-595, 2001.

Meroni M., Rossini M., Guanter L. et al.: Remote sensing of solar-induced chlorophyll fluorescence. Review of methods and applications. - Remote Sens. Environ. 113: 2037-2051, 2009.

Mir R.R., Reynolds M., Pinto F. et al.: High-throughput phenotyping for crop improvement in the genomics era. Plant Sci. 282: 60-72, 2019.

Mishra A., Heyer A.G., Mishra K.B.: Chlorophyll fluorescence emission can screen cold tolerance of cold acclimated Arabidopsis thaliana accessions. - Plant Methods 10: 38, 2014.

Mishra K.B., Mishra A., Novotná K. et al.: Chlorophyll a fluorescence under half of the adaptive growth-irradiance, for high-throughput sensing of leaf-water deficit in Arabidopsis thaliana accessions. - Plant Methods 12: 46, 2016.

Mohammed G.H., Colombo R., Middleton E.M. et al.: Remote sensing of solar-induced chlorophyll fluorescence (SIF) in vegetation: 50 years of progress. - Remote Sens. Environ. 231: 111177, 2019.

Morales F., Belkhodja R., Goulas Y. et al.: Remote and nearcontact chlorophyll fluorescence during photosynthetic induction in iron-deficient sugar beet leaves. - Remote Sens. Environ. 69: 170-178, 1999.

Moreno J. (ed.): Remote Sensing - Special Issue: 'Remote Sensing of Vegetation Fluorescence and Photosynthetic Efficiency', 2017.

Moustakas M., Hanć A., Dobrikova A. et al.: Spatial heterogeneity of cadmium effects on Salvia sclarea leaves revealed by chlorophyll fluorescence imaging analysis and laser ablation inductively coupled plasma mass spectrometry. - Materials 12: 2953, 2019.

Muller R., Schreiber U., Escher B. et al:: Rapid exposure assessment of PSII herbicides in surface water using a novel chlorophyll $a$ fluorescence imaging assay. - Sci. Total
Environ. 401: 51-59, 2008.

Munns R., James R.A., Sirault X.R.R. et al.: New phenotyping methods for screening wheat and barley for beneficial responses to water deficit. - J. Exp. Bot. 61: 3499-3507, 2010.

Nedbal L., Soukupová J., Kaftan D. et al.: Kinetic imaging of chlorophyll fluorescence using modulated light. - Photosynth. Res. 66: 3-12, 2000.

Nedbal L., Whitmarsh J.: Chlorophyll fluorescence imaging of leaves and fruits. - In: Papageorgiou G.C., Govindjee (ed.): Chlorophyll $a$ Fluorescence. Advances in Photosynthesis and Respiration. Vol. 19. Pp. 389-407. Springer, Dordrecht 2004.

Niyogi K.K., Björkman O., Grossman A.R.: Chlamydomonas xanthophyll cycle mutants identified by video imaging of chlorophyll fluorescence quenching. - Plant Cell 9: 13691380, 1997.

Noble E., Kumar S., Görlitz F.G. et al.: In vivo label-free mapping of the effect of a photosystem II inhibiting herbicide in plants using chlorophyll fluorescence lifetime. - Plant Methods 13: 48, 2017.

Omasa K., Shimazaki K.-I., Aiga I. et al.: Image analysis of chlorophyll fluorescence transients for diagnosing the photosynthetic system of attached leaves. - Plant Physiol. 84: 748-752, 1987.

Ooms D., Destain M.-F.: Evaluation of chicory seeds maturity by chlorophyll fluorescence imaging. - Biosyst. Eng. 110: 168177, 2011.

Ortiz-Bustos C.M., Pérez-Bueno M.L., Barón M., Molinero-Ruiz L.: Use of blue-green fluorescence and thermal imaging in the early detection of sunflower infection by the root parasitic weed Orobanche cumana Wallr. - Front. Plant Sci. 8: 833, 2017.

Osmond C.B., Berry J.A., Balachandran S. et al.: Potential consequences of virus infection for shade-sun acclimation in leaves. - Plant Biol. 103: 226-229, 1990.

Oxborough K.: Using chlorophyll $a$ fluorescence imaging to monitor photosynthetic performance. - In: Papageorgiou G.C., Govindjee (ed.): Chlorophyll $a$ Fluorescence. Advances in Photosynthesis and Respiration. Vol. 19. Pp. 409-428. Springer, Dordrecht 2004.

Oxborough K., Hamlon A.R.M., Underwood G.J.C., Baker N.R.: In vivo estimation of the photosystem II photochemical efficiency of individual microphytobenthic cells using highresolution imaging of chlorophyll $a$ fluorescence. - Limnol. Oceanogr. 45: 1420-1425, 2000.

Papageorgiou G.C.: Chlorophyll fluorescence: an intrinsic probe of photosynthesis. - In: Govindjee (ed.): Bioenergetics of Photosynthesis. Pp. 319-371. Academic Press, New York 1975.

Penella C., Pina A., San Bautista A. et al.: Chlorophyll fluorescence imaging can reflect development of vascular connection in grafting union in some Solanaceae species. Photosynthetica 55: 671-678, 2017.

Pérez-Bueno M.L., Ciscato M., vandeVen M. et al.: Imaging viral infection: studies on Nicotiana benthamiana plants infected with the pepper mild mottle tobamovirus. - Photosynth. Res. 90: 111, 2006.

Pérez-Bueno M.L., Pineda M., Barón M.: Phenotyping plant responses to biotic stress by chlorophyll fluorescence imaging. - Front. Plant Sci. 10: 1135, 2019.

Pérez-Bueno M.L., Pineda M., Cabezza F.M., Barón M.: Multicolour fluorescence imaging as a candidate for disease detection in plant phenotyping. - Front. Plant Sci. 7: 1790, 2016.

Pfanz H., Mombour J., Wittmann C. et al:: Chlorophyll fluorescence for visualizing the spatial and temporal spread of Phytophthora alni subsp. alni in alder bark tissue. - Plant 
Pathol. 64: 467-477, 2015.

Phinney N.H., Solhaug K.A., Gauslaa Y.: Rapid resurrection of chlorolichens in humid air: specific thallus mass drives rehydration and reactivation kinetics. - Environ. Exp. Bot. 148: 184-191, 2018.

Phinney N.H., Solhaug K.A, Gauslaa Y.: Photobiont-dependent humidity threshold for chlorolichen photosystem II activation. - Planta 250: 2023-2031, 2019.

Pieczywek P.M., Cybulska J., Szymańska-Chargot M. et al.: Early detection of fungal infection of stored apple fruit with optical sensors - Comparison of biospeckle, hyperspectral imaging and chlorophyll fluorescence. - Food Control 85: 327-338, 2018.

Pineda M., Pérez-Bueno M.L., Barón M.: Detection of bacterial infection in melon plants by classification methods based on imaging data. - Front. Plant Sci. 9: 164, 2018.

Pinto F., Damm A., Schickling A. et al.: Sun-induced chlorophyll fluorescence from high-resolution imaging spectroscopy data to quantify spatio-temporal patterns of photosynthetic function in crop canopies. - Plant Cell Environ. 39: 15001512, 2016.

Pinto F., Müller-Linow M., Schickling A. et al.: Multiangular observation of canopy sun-induced chlorophyll fluorescence by combining imaging spectroscopy and stereoscopy. Remote Sens.-Basel 9: 415, 2017.

Prinzenberg A.E., Víquez-Zamora M., Harbinson J. et al.: Chlorophyll fluorescence imaging reveals genetic variation and loci for a photosynthetic trait in diploid potato. - Physiol. Plantarum 164: 163-175, 2018.

Rascher U., Alonso L., Burkart A. et al.: Sun-induced fluorescence - a new probe of photosynthesis: first maps from the imaging spectrometer HyPlant. - Glob. Change Biol. 21: 4683-4684, 2015.

Rascher U., Lüttge U.: High-resolution chlorophyll fluorescence imaging serves as a non-invasive indicator to monitor the spatio-temporal variations of metabolism during the daynight cycle and during the endogenous rhythm in continuous light in the CAM plant Kalanchoë daigremontiana. - Plant Biol. 4: 671-681, 2002.

Rees H., Duncan S., Gould P. et al.: A high-throughput delayed fluorescence method reveals underlying differences in the control of circadian rhythms in Triticum aestivum and Brassica napus. - Plant Methods 15: 51, 2019.

Rolfe S.A., Scholes J.D.: Quantitative imaging of chlorophyll fluorescence. - New Phytol. 131: 69-79, 1995.

Rousseau C., Belin E., Bove E. et al.: High throughput quantitative phenotyping of plant resistance using chlorophyll fluorescence image analysis. - Plant Methods 9: 17, 2013.

Rousseau C., Hunault G., Gaillard S. et al:: Phenoplant: a web resource for the exploration of large chlorophyll fluorescence image datasets. - Plant Methods 11: 24, 2015a.

Rousseau D., Chéné Y., Belin E. et al.: Multiscale imaging of plants: current approaches and challenges. - Plant Methods 11: $6,2015 b$

Rühle T., Reiter B., Leister D.: Chlorophyll fluorescence video imaging: a versatile tool for identifying factors related to photosynthesis. - Front. Plant Sci. 9: 55, 2018.

Ryan K.G., Tay M.L., Martin A. et al.: Chlorophyll fluorescence imaging analysis of the responses of Antarctic bottom-ice algae to light and salinity during melting. - J. Exp. Mar. Biol. Ecol. 399: 156-161, 2011.

Sánchez-Moreiras A.M., Graña E., Reigosa M.J., Araniti F.: Imaging of chlorophyll $a$ fluorescence in natural compoundinduced stress detection. - Front. Plant Sci. 11: 583590, 2020.

Sandmann M., Grosch R., Graefe J.: The use of features from fluorescence, thermography, and NDVI imaging to detect biotic stress in lettuce. - Plant Disease 102: 1101-1107, 2018.

Scharte J., Schön H., Weis E.: Photosynthesis and carbohydrate metabolism in tobacco leaves during an incompatible interaction with Phytophthora nicotianae. - Plant Cell Environ. 28: 1421-1435, 2005

Schreiber U., Quayle P., Schmidt S. et al.: Methodology and evaluation of a highly sensitive algae toxicity test based on multiwell chlorophyll fluorescence imaging. - Biosens. Bioelectron. 22: 2554-2563, 2007.

Schreiber U., Schliwa U., Bilger W.: Continuous recording of photochemical and non-photochemical chlorophyll fluorescence quenching with a new type of modulation fluorometer. - Photosynth. Res. 10: 51-62, 1986.

Segečová A., Pérez-Bueno M., Barón M. et al.: Noninvasive determination of toxic stress biomarkers by high-throughput screening of photoautothrophic cell suspensions cultures with multicolour fluorescence imaging. - Plant Methods 15: 100, 2019.

Serôdio J., Schmidt W., Frommlet J.C. et al.: An LED-based multi-actinic illumination system for the high throughput study of photosynthetic light responses. - PeerJ 6: e5589, 2018.

Shakhnarovich G., Darrell T., Indyk P. (ed.): Nearest-Neighbor Methods in Learning and Vision. Pp. 280. MIT Press, Cambridge 2005.

Shu S., Tang Y., Yuan Y. et al.: The role of 24-epibrassinolide in the regulation of photosynthetic characteristics and nitrogen metabolism of tomato seedlings under a combined low temperature and weak light stress. - Plant Physiol. Bioch. 107: 344-353, 2016.

Siebke K., Weis E.: Assimilation images of leaves of Glechoma hederacea: analysis of non-synchronous stomata related oscillations. - Planta 196: 155-165, 1995.

Siegmann B., Alonso L., Celesti M. et al.: The high-performance airborne imaging spectrometer HyPlant - From raw images tot top-of-canopy reflectance and fluorescence products: introduction of an automated processing chain. - Remote Sens.-Basel 11: 2760, 2019.

Simkin A.J., McAusland L., Lawson T., Raines C.A.: Overexpression of the RieskeFeS protein increases electron transport rates and biomass yield. - Plant Physiol. 175: 134145, 2017.

Simko I., Hayes R.J., Furbank R.T.: Non-destructive phenotyping of lettuce plants in early stages of development with optical sensors. - Front. Plant Sci. 7: 1985, 2016.

Simko I., Jimenez-Berni J.A., Furbank R.T.: Detection of decay in fresh-cut lettuce using hyperspectral imaging and chlorophyll fluorescence imaging. - Postharvest Biol. Tec. 106: 44-52, 2015.

Sinha S.K., Padalia H., Patel N.R., Chauhan P.: Estimation of seasonal sun-induced fluorescence dynamics of Indian tropical deciduous forests using SCOPE and Sentinel-2 MSI. - Int. J. Appl. Earth Obs. Geoinf. 91: 102155, 2020.

Song X., Zhou G., Xu Z. et al.: Detection of photosynthetic performance of Stipa bungeana seedlings under climatic change using chlorophyll fluorescence imaging. - Front. Plant Sci. 6: 1254, 2016.

Sun D., Zhu Y., Xu H. et al.: Time-series chlorophyll fluorescence imaging reveals dynamic photosynthetic fingerprints of sos mutants to drought stress. - Sensors-Basel 19: 2649, 2019.

Sun J., Yang W., Feng M. et al.: An efficient variable selection method based on random frog for the multivariate calibration of NIR spectra. - RSC Adv. 10: 16245-16253, 2020.

Sundbom E., Björn L.O.: Phytoluminography: imaging plants by delayed emission. - Physiol. Plantarum 40: 39-41, 1977.

Taria S., Rane J., Alam B. et al.: Combining IR imaging, 
chlorophyll fluorescence and phenomic approach for assessing diurnal canopy temperature dynamics and desiccation stress management in Azadirachta indica and Terminalia mantaly.Agroforest. Syst. 94: 941-951, 2020.

Tietz S., Hall C.C., Cruz J.A., Kramer D.M.: NPQ ${ }_{(\mathrm{T})}$ : a chlorophyll fluorescence parameter for rapid estimation and imaging of non-photochemical quenching of excitons in photosystemII-associated antenna complexes. - Plant Cell Environ. 40: 1243-1255, 2017.

Trampe E., Kolbowski J., Schreiber U., Kühl M.: Rapid assessment of different oxygenic phototrophs and singlecell photosynthesis with multicolour variable chlorophyll fluorescence imaging. - Mar. Biol. 158: 1667-1675, 2011.

Tschiersch H., Junker A., Meyer R.C., Altmann T.: Establishment of integrated protocols for automated high throughput kinetic chlorophyll fluorescence analysis. - Plant Methods 13: 54-72, 2017.

van Bezouw R.F.H.M., Kuerentjes J.J.B., Harbinson J., Aarts M.G.M.: Converging phenomics and genomics to study natural variation in plant photosynthetic efficiency. - Plant J. 97: 112-133, 2019.

Verrelst J., Caicedo J.P.R., Muñoz-Marí J. et al.: SCOPE-based emulators for fast generation of synthetic canopy reflectance and sun-induced fluorescence spectra. - Remote Sens.-Base1 9: 927, 2017

Walker B.J., Busch F.A., Driever S.M. et al.: Survey tools for measuring in vivo photosynthesis. - In: Covshoff S. (ed.): Photosynthesis: Methods in Molecular Biology. Vol. 1770. Pp. 3-24. Humana Press, New York 2018.

Wang H., Qian X., Zhang L. et al.: A method of high throughput monitoring crop physiology using chlorophyll fluorescence and multispectral imaging. - Front. Plant Sci. 9: 407, 2018.

Wang L., Poque S., Valkonen J.P.T.: Phenotyping viral infection in sweetpotato using a high-throughput chlorophyll fluorescence and thermal imaging platform. - Plant Methods 15: 116, 2019.

Wangpraseurt D., Lichtenberg M., Jacques S.L. et al.: Optical properties of corals distort variable chlorophyll fluorescence measurements. - Plant Physiol. 179: 1608-1619, 2019.
Weber J.F., Kunz C., Peteinatos G.G. et al.: Utilization of chlorophyll fluorescence imaging technology to detect plant injury by herbicides in sugar beet and soybean. - Weed Technol. 31: 523-535, 2017.

Weis E., Berry J.A.: Quantum efficiency of photosystem II in relation to energy-dependent quenching of chlorophyll fluorescence. - BBA-Bioenergetics 894: 198-208, 1987.

Wen Z., Raffaello T., Zeng Z. et al.: Chlorophyll fluorescence imaging for monitoring effects of Heterobasidion parviporum small secreted protein induced cell death and in planta defense gene expression. - Fungal Genet. Biol. 126: 37-49, 2019.

Wingler A., Marès M., Pourtau N. et al.: Spatial patterns and metabolic regulation of photosynthetic parameters during leaf senescence. - New Phytol. 161: 781-789, 2004.

Wu Y., Zeng Y., Qu J.Y., Wang W.-X.: Mercury effects on Thalassiosira weissflogii: applications of two-photon excitation chlorophyll fluorescence lifetime imaging and flow cytometry. - Aquat. Toxicol. 110-111: 133-140, 2012.

Yao J., Sun D., Cen H. et al.: Phenotyping of Arabidopsis drought stress response using kinetic chlorophyll fluorescence and multicolor fluorescence imaging. - Front. Plant Sci. 9: 603, 2018.

Zeng Y., Wu Y., Li D. et al.: Two-photon excitation chlorophyll fluorescence lifetime imaging: a rapid and noninvasive method for the assessment of cadmium toxicity in a marine Thalassiosira weissflogii. - Planta 236: 1653-1663, 2012.

Zhao H., Wang L., Zhao F.-J. et al.: SpHMA1 is a chloroplast cadmium exporter protecting photochemical reactions in the Cd hyperaccumulator Sedum plumbizincicola. - Plant Cell Environ. 42: 1112-1124, 2019.

Zhao L.-J., Xie J.-F., Zhang H. et al.: Enzymatic activity and chlorophyll fluorescence imaging of maize seedlings (Zea mays L.) after exposure to low doses of chlorsulfuron and cadmium. - J. Integr. Agr. 17: 826-836, 2018.

Zhuang J., Wang Y., Chi Y. et al.: Drought stress strengthens the link between chlorophyll fluorescence parameters and photosynthetic traits. - PeerJ 8: e10046, 2020.

(C) The authors. This is an open access article distributed under the terms of the Creative Commons BY-NC-ND Licence. 